Joanna Saluk-Bijak

\title{
2. TOXICOLOGY
}

Toxicology is a science of poisons (Greek toxicon - poison, logos - science). The term poison applies to substances and their combinations whose minor quantities cause severe impairment of body functions or even death (poisoning). Poisons can act instantly or accumulate in the body causing chronic poisoning. The group of poisons covers toxic substances of natural origin (venoms, animal toxins or plant toxins) and synthetic chemical toxins.

Paracelsus, who lived in 1493-1541, was a physician and naturalist, called the father of contemporary medicine and also considered the father of toxicology. He was the author of the quotation used as the foundations of hormesis: "What is a poison? Everything is poisonous and nothing is poisonous, it's all a matter of dose". Paracelsus hence claimed that it is a dose and not the kind that makes a substance poisonous. Hormesis is a phenomenon involving a beneficial effect of a harmful factor on the body, if exposed to low instead of high doses of the factor.

Toxic action of a chemical substance depends then on its dose and concentration in a tissue/organ or system. Dose is the quantity of chemical substance administered, taken or absorbed into the body via a specific route, conditioning a lack or presence of specific biological effects, expressed by percentage of organisms responding to the dose. Usually the dose is expressed in weight units per body weight or area, and sometimes additionally per day. Depending on the effects caused by the absorbed substance, the following doses can be identified. One should remember, though, that the absorbed dose is not necessarily the same as the administered dose, which depends on the method of its penetration and transport of the substance.

Threshold (limit) dose - (dosis minima, DM) it is the minimum quantity of a substance that causes first visible biological effects, i.e. it is the lowest exposure level (lowest dose) causing changes which exceed the adaptation limits determining maintenance of the body homeostasis.

Therapeutic dose - (dosis therapeutica, dosis curtiva, DC) it is a quantity of a substance that demonstrates a pharmacotherapeutic effect, causes functional changes within physiological limits resulting in the desired therapeutic effect and does not impair physiological processes.

Toxic dose - (dosis toxica, DT) it is a quantity of a substance that causes a toxic effect after being absorbed into the body.

Lethal dose - (dosis letalis, DL) it is a quantity of a substance causing death after single administration. 
Nowadays, a number of toxic substances commonly used in industry, agriculture, everyday products, medicines, cosmetics etc. are produced as a result of civilizational progress and development of industry and different areas of chemistry. A human being is permanently exposed to the substances, while the degree of their toxicity for a living organism depends on a number of factors, first and foremost including the dose taken, which depends on the time of the body exposure to the substance.

The term exposure defines a physical contact of a living organism with a chemical, physical or biological factor, described by concentration or intensity and duration. A chemical substance can be taken during exposure and then absorbed, which is expressed by the absorbed dose. The presence of a chemical substance in samples of biological material (inhaled air, body fluids, tissue preparations) provides an immediate evidence of exposure, however a lack of chemical substance in the samples is not a testimony to a lack of exposure. Exposure can also be identified by a substance concentration in the air or water and expressed as the dose taken, i.e. quantity of substance introduced into the body via a medium such as air, potable water or ingested food.

Xenobiotics are foreign substances that a living organism is exposed to (Gr. ksenos - foreign, biotikos - applying to life). They are substances that do not occur naturally in the body. A special group of xenobiotics covers chemical compounds produced by humans by means of synthesis. Their chemical structure does not occur naturally and that is why living organisms did not adapt to their action during earlier evolution.

Toxicology is a discipline of science that developed initially on the basis of practical observations made by subsequent generations, helping to identify toxic properties of specific substances, causing poisoning and/or death in humans. Plant poisons were used to commit suicide, murder or execute a death penalty. Deepening of the knowledge of different ways to detect poisons after their application, possibilities of using the substances for medical purposes and use of potential antidotes once a poison was overdosed constituted an important research area.

As time went by, new methodologies emerged and different areas of science developed, which contributed to a dynamic and multi-directional development of toxicology.

With regard to prevalence and great diversity of xenobiotics, contemporary toxicology covers a number of issues concerning actual and potential danger related to the action of chemicals on living organisms and ecosystems.

The role of contemporary toxicology is to spread the knowledge of harmful action of chemicals and methods to control and prevent their harmful action, to carry out scientific research to prevent adverse effects of xenobiotics by limiting their toxicity, and to develop methods of poisoning diagnosis and treatment. 
Toxicology has become an interdisciplinary area combining information from such fields as biology, chemistry, biochemistry, genetics, immunology, physiology, medicine, epidemiology, pathology, criminology and pharmacy. A wide range of toxicology issues can be classified within different subdisciplines of toxicology such as neurotoxicology, immunotoxicology, genetic toxicology, molecular toxicology and toxicological analysis.

The nature of toxicological hazards has changed completely in contemporary toxicology alongside with large-scale urbanisation and industrialisation as well as development of different areas of science.

Cases of chronic poisoning, resulting from long-term (not consciously intended) effect of small doses of chemical substances on a living organism, and often on large human populations e.g. in a workplace or living environment, are the main problem of contemporary toxicology.

Formation of large conurbations has become the main cause of pollution to atmosphere, surface waters and soils, and consequently of food. Industrialisation entails common use of chemicals, e.g. detergents and other cleaning agents, cosmetics, pharmaceuticals, paints and varnishes, etc. The situation is additionally aggravated by common use of stimulants, including intensive development of new forms on synthetic psychotropic substances.

Owing to complexity of issues related to contemporary toxicology, it was divided into several separate areas. Toxicology is a separate discipline of science but a detailed nature of its issues entailed the need to identify separate areas of toxicology.

They are as follows:

- clinical toxicology that is a scientific discipline and medical specialisation involving diagnostics, prevention and interpretation of cases of acute poisoning as well as chronic poisoning mainly as a result of industrialisation;

- toxicology of medical drugs that deals with adverse effects of pharmaceuticals (side effects of medical drugs administered in therapeutic doses, toxic effects of intended or incidental overdosing of medicines or when therapeutic doses are used in a wrong way), studies on possible modifications of toxic drug symptoms by different factors including age, sex, nutrition, health condition, genetic determinants, interactions with other pharmaceuticals or other toxic factors (e.g. alcohol, drugs), pre-clinical studies of potential medicines and addictions to medicines and other substances.

- forensic toxicology mainly used by justice, and covering lifetime and post-death chemical analysis of poisoning with xenobiotics; first and foremost it deals with detection of toxic substances in biological material collected post mortem, and in majority of cases applies to diagnostics of alcohol, psychotropic drugs and doping substances;

- food toxicology aimed at an analysis of food composition for toxicity of substances introduced during cultivation, production and processing, and to 
improve the qualities and storage capacity; it also covers toxicological safety of packaging and food contamination;

- occupational toxicology which is related to occupational health and medicine; it covers prevention, diagnostics and treatment of occupational poisoning, chemical substances occurring in a workplace to identify hazardous factors, and acute and chronic diseases they may cause; it also determines acceptable conditions of safe use of toxic substances and actions to prevent their absorption; it identifies the acceptable exposure limit for humans in their workplace, develops standards related to the content of chemicals in the air at work stations and identifies and evaluates exposure biomarkers;

- environmental toxicology which covers the impact of air, water and soil contamination on human health and preventive actions and controls to avoid exceeding the standards of chemical contaminant content in different elements of the environment; environmental toxicology evaluates the impact of toxic substances on the human body but also on animals, plants and functioning of whole ecosystems; it also deals with environmental and biological monitoring, i.e. regular measurements of the concentration of toxic compounds in the environment or biological material.

Contemporary people stay in an environment in which they are permanently exposed to the action of xenobiotics, which penetrate into their bodies via different routes.

Physical and chemical characteristics of toxic substances (volatility, solubility in water, readiness for sorption by solids) determine their penetration route into the ecosystem and mobility in atmosphere, water or soil. Introduction of toxic substances into the ecosystem is the first step of exposure of a body in which some functions are impaired as a result of increasing modifications in tissues and organs.

Defence mechanisms of a living organism enable metabolising and removal of xenobiotics. However, if the supply of the contaminant is greater than the body's capacity to metabolise and excrete, it accumulates in the body tissues, which is called bioaccumulation. Poorly degradable substances are very persistent and accumulate easily. Consequently, the organisms involved can be subjected to population changes. Individuals in such populations become weak, their reproduction capacity deteriorates, ability to give birth to healthy offspring decreases and the mortality of organisms exposed to toxic substances goes up.

Interactions of organisms in an ecosystem form a complex network of relations. They include food chains and complex trophic networks. When a toxic substance enters a trophic chain, a xenobiotic concentration is observed due to a multiple increase in the substance bioconcentration i.e. its concentration in the body tissues. The phenomenon is known as biomagnification. When one species eats other ones, it accumulates growing quantities of the xenobiotic, a poorly degradable one in particular. A human being on the top of a trophic chain is then exposed to highly concentrated contaminations. 
Poorly degradable, highly persistent and bioaccumulative xenobiotics reveal the greatest impact on the environment, ecosystems and living organisms. They are relatively mobile in the air, water and soil, and are characterised by transport and biomagnification in the chain of trophic relations.

\subsection{Toxicometry}

Toxicometry is an area of toxicology aimed to assess toxicity of a substance. Cases of chronic poisoning, related to long-lasting impact of small doses of chemical substances on the body, usually applying to large human populations, are among major problems of contemporary toxicology. The issues are mainly related to occupational toxicology including exposure of humans in their workplace, and environmental toxicology - industrial toxicology in this case - applying to contamination of atmosphere (gases generated during fuel combustion in power plants, emissions from industrial plants (metallurgical and chemical plants in particular), products of crude oil and petrol combustion in mechanical vehicles), surface waters and soil (food contamination).

Occupational and environmental exposure is usually of complex nature and related to a simultaneous impact of several chemicals, which entails the need for extensive toxicological analysis for a compound toxicity assessment to identify the acceptable exposure limit for humans.

Exposure is assessed by environmental and biological monitoring. From the point of view of toxicology, biomonitoring stands for activities aimed to assess the condition of the environment by means of bioidentifiers (biomarkers), including in particular the degree of air and water pollution. It involves regular measurements of concentration of toxic compounds in the environment or biological material facilitating comparison of the values and concentrations under different conditions, and identification of trends in time.

Biological monitoring is an important tool used for assessment of exposure and intake volume of chemicals in humans. The results of environmental monitoring are used to evaluate its contamination and the related hazard for living organisms. Such studies help to introduce the right method of limiting the source of harmful factors and to eliminate them.

Assessment of environmental or occupational exposure by biological monitoring involves identification of selected biomarkers in a biological material and establishing of the actual dose taken. It helps to identify the total intake of xenobiotics by all routes - with air, food or directly through the skin (drugs, cosmetics, cleaning agents). Complex analytical strategies combined with appropriate sampling methods facilitate qualitative and quantitative assessment of environmental (occupational) pollution and often help to identify their sources. 


\subsubsection{Biomarkers (bioidentifiers)}

A biomarker is a wide term covering identification of parameters reflecting interactions between a biological system and environmental factors. A qualitative correlation in the biological material with the quantity of absorbed xenobiotic is an essential feature which qualifies a compound as a biomarker of exposure to the reference xenobiotic. Furthermore, a substance used as a biomarker should be easy to isolate from a biological material and persistent in analysis. A biomarker is a measurable marker of changes occurring in a body following absorption of a xenobiotic, and is the evidence of a toxin absorption into the body and a valuable source of important information.

The National Institute of Health introduced a standardised definition of a biomarker in 2001. The Institute identified a biomarker as a feature that can be objectively measured and then used as an indicator in an assessment of physiological biological processes, pathological processes or a body's response to therapeutic actions.

An analysis of biomarkers provides information on:

- occurrence of a body exposure to a harmful factor (exposure biomarker);

- health effects caused in the body following exposure to a xenobiotic (effect biomarker);

- body sensitivity to a specific xenobiotic action (sensitivity biomarker).

Exposure biomarkers are substances or their metabolites or products of interaction between a xenobiotic and body molecules measurable in the biological material and exogenous for the body. If a xenobiotic metabolism in the body is known, the volume of the absorbed xenobiotic dose and the resulting risk for health can be assessed by identifying the biomarker level. Exposure biomarkers are then intended for qualitative and quantitative analysis of exposure.

Effect biomarkers provide information about changes occurring in the body following action of a toxic factor. They are measurable biochemical, physiological, structural (including molecular changes on a sub-cellular level), behavioural and other changes occurring in the body as a result of action of a xenobiotic. Their analysis is an important element of health monitoring in employees exposed to harmful substances. A body's response to penetration of a toxic substance covers a wide spectrum of changes from transient, asymptomatic to permanent clinical changes with disease manifestations. An effect biomarker is identified by assessment of new health disorders and diseases or based on total effects with the existing disorders. The indicators are useful in early detection of diseases, which is their advantage. Biomarkers can also serve scheduling of medical treatment and prognosis.

Sensitivity biomarkers are indicators of congenital (genetically conditioned) or acquired body's ability to respond once exposed to a specific xenobiotic. 
They provide information if one should expect adverse health effects in a specific organism or populations in relation to a reference exposure dose volume. They are useful in identification of the probability of a disease development following exposure to a toxin.

\subsubsection{Assessment of the degree of harmful effect}

The objective of toxicometric studies is to detect an adverse effect of a compound and to develop its qualitative and quantitative characteristics. Toxicometry studies quantitative relationships between a xenobiotic concentration and its toxic effect on the body, namely severity of the harmful effect of different chemical substances. It is aimed to establish concentrations of toxic substances safe for the environment and humans. Characteristics of xenobiotics provides a basis for explaining the mechanisms of their toxic action and helps to develop rules to prevent poisoning: appropriate protection during production, transport, storage and distribution of the substance.

One strives to identify acceptable parameters of human and natural environment exposure, which is expressed numerically as acceptable concentration in the air in production plants, atmosphere, potable water and food. The acceptable daily doses that a human can take with no adverse effects for health are also identified.

For understandable reasons, toxicometric studies are not performed on humans but unfortunately laboratory animals are used for this purpose. That is why the results of toxicometric studies have to be extrapolated from laboratory animals to humans. It is difficult to predict the impact of a xenobiotic on a human body based on the results of tests on animals and it can suffer from a serious error. Adequate interpretation of results in reference to humans depends on selection of the right species of test animals and the right methods of extrapolation of results.

In an optimum study array the conditions are selected so that a toxic compound and exposure conditions (exposure route and time) and biological system (animal species, age and sex) were the same as the conditions of human exposure. The condition can be hardly fulfilled and that is why in order to obtain appropriate toxic effects under experimental conditions, within a specific period of time, laboratory animals are exposed to much higher doses of toxic substances than humans (during a longer period of time). To that end extrapolation of results from high to low doses is necessary. Recalculation of the dose administered to an animal per body weight of a human is the simplest but also the least precise method of extrapolation of results.

In order to assess toxic action on humans in a precise way, based on analyses carried out on laboratory animals, one should take the following facts into consideration:

- differences between species in their resistance/sensitivity to different xenobiotics; 
- difficulty in recognising mild adverse effects in animals, e.g. headache;

- differences in resistance to the action of xenobiotics may result from the impact of different internal and external factors such as body nutrition and general fitness, living conditions, medical drugs taken, kind of job etc.

Toxicometric studies are finally intended to establish levels of chemical safe for humans. The identified levels are of different nature and hence applied in different ways. Based on toxicometric studies, the values of the highest acceptable chemical and dust concentrations (safe concentrations at long-lasting exposure) and safe intensities for physical factors harmful for health in the working environment are identified and expressed as follows:

- highest acceptable concentration (HAC) of a substance in the air (and analogically the highest acceptable dose (HAD) e.g. in water) measured in the plant environment to protect the staff against poisoning in the work place, stands for the weighted average concentration of a harmful factor whose impact on the employee during an 8-hour working day and the average weekly working time, specified in the Labour Code, during their working career, should not cause negative changes in the employee's health or health of his/her future generations;

- highest acceptable momentary concentration (HAMC) measured in the work environment stands for the mean concentration of a factor harmful for health in the air in the work environment, which should not cause negative effects on an employee's health or his/her future generations, if it occurs at a work station for up to 15 minutes and no more than twice per shift, at time interval not shorter than 1 hour;

- highest acceptable threshold concentration (HATC) is measured in the work environment as a concentration of a factor harmful for health, which must never be exceeded in the work environment considering a hazard for the life or health of employees;

- highest biological concentration (HBC) is the acceptable concentration of toxic substances or their metabolites in the blood or urine.

- Other parameters of hygienic standards used in environment and health protection include:

- highest acceptable concentration of a substance in the atmosphere to protect health of the population, mainly in large conurbations and near industrial plants emitting harmful pollutions;

- allowable daily intake (ADI) specifying the quantity of a substance that can be safely ingested by humans with food and water every day, during whole life, usually expressed in $\mathrm{mg} / \mathrm{kg}$ body weight;

- allowable weekly intake (AWI) specifying the quantity of a substance that can be safely ingested by humans with food and water weekly, during whole life, usually expressed in $\mathrm{mg} / \mathrm{kg}$ body weight.

The results obtained in toxicometric studies, developed as dose-effect and dose-response relationships are the starting point to identify the abovementioned 
standards. Toxicometric studies are based on observing the relationship between a toxic effect of a substance and its dose. A biological change caused by an action of a toxic compound is called an effect. In some cases an effect can only be identified qualitatively, while in other cases - if possible - the body response to a xenobiotic is identified quantitatively.

\section{Dose-effect relationship}

A dose-effect relationship occurs when the effect is of quantitative nature - it is stronger or weaker depending on the administered dose and can be expressed in a numerical form, reflecting the changes observed in an individual (e.g. change in the activity of an enzyme). The numerical relationship is established following several measurements of the effect in different individuals and at different doses of the substance. The dose-effect relationship helps to draw two types of conclusions:

- based on a specific dose value, a conclusion concerning the effect can be drawn;

- based on the observed effect one can estimate the dose volume that caused the effect.

The results of such an analysis should be approached with care as characteristics of an individual and population as well as different external factors can affect the relationship.

\section{Dose-response relationship}

In some cases reactions of the body to xenobiotics can only be described in qualitative aspects, which means that a reaction to a xenobiotic or no reaction is observed, with no intermediate conditions. Assessment of the effect in then limited only to a "yes" or "no" statement. Examples of such relationships include a lethal effect (the animal died or not), cancerogenesis (a tumour occurred or not). Such effects are known as individual or quantal effects. They may become aggravated at higher doses but the intensity of a quantal reaction is studied in a population of animals (group) and not in an individual. Exposing populations of living organisms to increasing doses of toxic substances is a classic example of studying the dose-response relationship. The reaction intensity is expressed in per cent as a percentage of individuals in the population in which the effect of a specific toxin dose was observed. A population reaction expressed this way is called a response. The intensity stands for a dose-response relationship, which takes a form of a sigmoid curve.

Based on studies of the dose-response relationship, the concept of mean lethal dose $\left(\mathbf{L D}_{\mathbf{5 0}}\right)$ was introduced. $\mathrm{LD}_{50}$ tends to be expressed in $\mathrm{mg} / \mathrm{kg}$ of body weight and identifies the dose of a poison which causes death of a half (50\%) of the population of laboratory animals which received the poison. Sometimes it is 
considered a measure of the dose-response relationship and is used for qualitative comparison of acute toxicity of different xenobiotics.

An analogical volume for inhaled poisons is known as the mean lethal concentration $\left(\mathbf{L C}_{50}\right)$ and applies to the xenobiotic concentration in the inhaled air.

The assessment of the dose-response relationship for threshold effects covers identification of the risk level of using a chemical by identifying the NOAEL and LOAEL values while maintaining a safety margin when the results obtained for laboratory animals are extrapolated to humans. NOAEL (No Observable Effect Level) - the highest dose or exposure level in studies enabling identification of the dose-response relationship for which no statistically or biologically significant increase in the prevalence or aggravation of adverse effects of the substance is observed in the studied animals as compared to the control group. LOAEL (Lowest Observed Adverse Effect Level) - the lowest dose or exposure level in studies enabling identification of the dose-response relationship in experimental animals for which statistically or biologically significant increase in the prevalence of adverse effects of the substance is observed in the studied animals as compared to the control group.

A non-threshold effect is observed in the studies of the dose-response relationship assessing toxicity of xenobiotics. The phenomenon applies to genotoxic substances for which the carcinogenic effect threshold cannot be identified. The probability of elevated risk of an additional tumour occurrence is specified for the substances and $T_{25}$ parameter is determined to that end. $T_{25}$ is a chronically administered dose which causes tumours in $25 \%$ of the exposed animals in a specific organ, corrected by spontaneous frequency in the average life of the reference animal species. Then, the value is converted into the $\mathrm{HT}_{25}$ parameter applying to humans, as follows:

$\mathrm{HT}_{25}=\mathrm{T}_{25} /(\text { body weight of a human/ body weight of an animal })^{0.25}$

\subsubsection{Assessment of a xenobiotic toxicity}

The effects of exposure to toxic substances can be local, systemic or delayed, and their severity can be acute or chronic. With regard to the poison dynamics, mechanism and effect on the body, poisoning can be divided into the following groups:

- acute poisoning which is characterised by rapid development of adverse changes in the body, occurring within a short time after introducing a single dose of a poison by ingestion, inhalation or application to the skin; it is generally characterised by high dynamics of clinical symptoms; symptoms of injury/ damage or death occur not later than within 24 hours;

- subacute poisoning - when adverse effects in the body are less violent after a single or multiple dose of the substance;

- chronic poisoning which occurs as a result of small doses of a poison, administered for a long period of time, usually as a result of the 
poison accumulation in the body; they tend to be caused by incidental poisoning, e.g. occupational poisoning is usually chronic; the concentration of toxic substances polluting human environment is normally so low that it causes chronic effect.

Based on studies of acute toxicity in animals, Hodge and Sterner (USA) classified toxic substances dividing them into 6 groups, depending on the $\mathrm{LD}_{50}$.

Table1. Poison toxicity scale according to Hodge and Sterner

\begin{tabular}{|c|l|c|c|c|c|}
\hline $\begin{array}{c}\text { Toxicity } \\
\text { grade }\end{array}$ & Name & $\begin{array}{c}\text { Oral LD } \\
\text { (g/kg body } \\
\text { weight); rats }\end{array}$ & $\begin{array}{c}\text { Dermal LD } \\
\text { (go/kg body } \\
\text { weight); } \\
\text { rabbits }\end{array}$ & $\begin{array}{c}\text { LD } \\
\text { Inhalation } \\
\text { rats }\end{array}$ & $\begin{array}{c}\text { Probable lethal } \\
\text { dose for an } \\
\text { adult human } \\
\text { in grams }\end{array}$ \\
\hline 1 & $\begin{array}{l}\text { Extremely } \\
\text { toxic }\end{array}$ & $\leq 0.001$ & $\leq 0.005$ & $\leq 10$ & $\approx 0.065$ \\
\hline 2 & $\begin{array}{l}\text { Highly } \\
\text { toxic }\end{array}$ & 0.05 & 0.043 & 100 & 4 \\
\hline 3 & $\begin{array}{l}\text { Moderately } \\
\text { toxic }\end{array}$ & 0.5 & 0.34 & 1000 & 30 \\
\hline 4 & $\begin{array}{l}\text { Slightly } \\
\text { toxic }\end{array}$ & 5.0 & 2.81 & 10000 & 250 \\
\hline 5 & $\begin{array}{l}\text { Practically } \\
\text { non-toxic }\end{array}$ & 15.0 & 22.6 & 100000 & 1000 \\
\hline 6 & $\begin{array}{l}\text { Relatively } \\
\text { harmless }\end{array}$ & $>15.0$ & $>22.6$ & $>100000$ & $>1000$ \\
\hline
\end{tabular}

A valid EU classification of chemical substances covers 4 classes, according to the scale of their toxicity based on $\mathrm{LD}_{50}$, following ingestion (Directive of the Council No. 92/32/EEC of 30 April 1992).

Table 2. Poison toxicity classes

\begin{tabular}{|l|c|l|}
\hline \multicolumn{1}{|c|}{$\begin{array}{c}\text { LD } \\
\text { s0 } \\
\text { range (mg/kg body weight identified } \\
\text { with a classic method) }\end{array}$} & \multicolumn{2}{|c|}{ Toxicity class/symbol } \\
\hline $\mathrm{LD}_{50}<25$ & I & Very toxic $(\mathrm{T}+)$ \\
\hline $25<\mathrm{LD}_{50}<200$ & II & Toxic (T) \\
\hline $200<\mathrm{LD}_{50}<2000$ & III & Harmful $(\mathrm{Xn})$ \\
\hline $2000<\mathrm{LD}_{50}$ & IV & $\begin{array}{l}\text { Not classified (practically } \\
\text { not harmful) }\end{array}$ \\
\hline
\end{tabular}


The effects of toxic substances are divided into local and systemic. They can occur in the area of:

- absorption - skin, eyes, nasal mucous membrane, lungs, alimentary tract;

- metabolic transformations - liver, lungs, kidneys, alimentary tract;

- accumulation (deposition) - kidneys, central nervous system, liver;

- excretion - liver, alimentary tract, kidneys, urine bladder;

- special sensitivity - gonads, secretory glands, haematopoietic system.

Local effects - they are pathological changes occurring in the direct contact area of a xenobiotic with the body surface, i.e. skin, mucous membrane and eyeball. Local effects are divided into irritating and sensitising.

Systemic effects - they are changes in the central and peripheral nervous system, alimentary tract, excretory system, cardiovascular system etc.

\subsubsection{Relationship between biological activity of a toxic substance and its chemical structure (examples)}

From the qualitative and quantitative point of view toxic effects depend on the chemical structure of a substance. There are several general rules describing the relationship between the degree of toxicity and structure of chemical compounds, including the type of a substituent added or the chain length.

- The more complex the chain branch is, the more toxic aliphatic hydrocarbons become.

- Unsaturated hydrocarbons (benzene) are more toxic than saturated ones (cyclohexane).

- Adding an -OH group to an aromatic compound increases its toxicity (phenol is more toxic than benzene) and decreases the toxicity, if added to an aliphatic compound (glycerol is less toxic than propanol).

- Substituents increasing toxicity of the following compounds: $-\mathrm{NH}_{2}-\mathrm{NO}_{2}$, $-\mathrm{NO},-\mathrm{CN},-\mathrm{F}$ and $-\mathrm{CH}_{3}$ in cyclic compounds.

- Substituents reducing toxicity of compounds include $-\mathrm{COOH},-\mathrm{SO}_{3} \mathrm{H}$, $-\mathrm{SH},-\mathrm{CH}_{3} \mathrm{CO},-\mathrm{CH}_{3} \mathrm{O},-\mathrm{C}_{2} \mathrm{H}_{5} \mathrm{O}$ and $-\mathrm{N}=\mathrm{N}-$.

- Lipophilic compounds penetrate more easily through protein and lipid membranes, and interact with receptors and accumulate in the lipid tissue quicker.

Substances are divided into the following kinds, depending on their chemical structure:

- irritants cause irritation of the mucous membrane and cornea; they include highly volatile liquid substances transforming into toxic gases. Poisoning with toxic gases greatly depends on their solubility in water. Highly soluble and quickly hydrolysing gases such as: $\mathrm{NH}_{3}$, formaldehyde ( $\mathrm{HCHO}$ ), hydrogen cyanide $\mathrm{HCN}$ and acid pairs: $\mathrm{HCl}, \mathrm{HF}, \mathrm{HNO}_{3}$ and $\mathrm{H}_{2} \mathrm{SO}_{4}$ have a toxic effect primarily on the respiratory tract; gases less soluble in water such as: $\mathrm{F}_{2}, \mathrm{CL}_{2}$ , $\mathrm{Br}_{2}, \mathrm{H}_{2} \mathrm{~S}$ and $\mathrm{SO}_{2}$ affect the mucous membrane along the whole respiratory 
tract, while gases with the lowest solubility in $\mathrm{H}_{2} \mathrm{O}$ including: nitrogen oxides, phosgene $\left(\mathrm{COCl}_{2}\right)$, ozone, phosphoric chlorides mainly affect the walls of the lung alveoli;

- asphyxiant gases whose toxic effect results only from competitive reduction of oxygen concentration in the air include: $\mathrm{N}_{2}, \mathrm{Ar}, \mathrm{He}$ and $\mathrm{Ne}$, while other biologically inactive gases form explosive mixtures with air before they reach suffocating concentration;

- narcotic substances initially stimulate the central nervous system to impede its functions afterwards; they include organic solvents (e.g. methanol) absorbed by ingestion, inhalation or dermally; the narcotic effect of aliphatic alcohols, alkenes, hydrogen chloro-derivatives, ketones and esters increases with a higher number of C atoms in the molecule (Richardson's law, 1869);

- caustic substances usually cause local superficial burns following a direct contact; they mainly include concentrated solutions of hydroxides: $\mathrm{NaOH}$, $\mathrm{NH}_{3} \mathrm{xH}_{2} \mathrm{O}, \mathrm{KOH}$ and alkaline chlorates: $\mathrm{NaOCl}, \mathrm{KOCl}$ as well as highly toxic inorganic acids: $\mathrm{HCl}, \mathrm{HNO}_{3}$ and $\mathrm{H}_{2} \mathrm{SO}_{4}$; caustic organic acids include: acetic acid, formic acid, lactic acid, oxalic acid, carbolic acid and its derivatives (e.g. cresol and Lysol);

- phosphorus organic compounds which are acetylcholinesterase inhibitors (AChE);

- heavy metals ( $\mathrm{As}, \mathrm{Cr}, \mathrm{Cd}, \mathrm{Pb}, \mathrm{Hg}, \mathrm{Cu}$ and $\mathrm{Zn}$ ) metal compounds soluble in water or body fluids have a stronger toxic effect; some elements form metalorganic combinations; generally, they are characterised by specific bioaccumulation which leads to a one-off inclusion of large quantities of the accumulated metal into the metabolic pool as a result of a discharge mechanism such as e.g. stress factor or pathogen;

- aromatic and amine-derivative nitro compounds - methaemoglobinforming compounds.

\subsubsection{Objectives and directions of toxicometric studies}

Studies to assess toxic effect of compounds consist of several stages. Any subsequent stage can be performed once justified by the results obtained on the previous one.

\section{Stages of toxicometric procedure studies (and selection)}

\section{Assessment of physical and chemical characteristics of a compounds and determining its toxicity.}

Based on an analysis of the chemical structure of a studied compound and comparing it with data concerning related compounds, its potential toxic properties can be determined. The knowledge of the relationship between the 
chemical structure and biological activity plays an important role on this stage. The analysis shall take into account the impact of physical and chemical characteristics on the toxicity of related compounds e.g. chain length or substituent type.

2. Acute toxicity assessment and identification of $L D_{50}$ combined with:

- assessment of irritating effect;

- assessment of sensitising effects;

- additional studies (including toxicity assessment depending on the administration route and initial studies concerning metabolism and toxicokinetics).

Acute toxicity is a strong toxic effect occurring shortly after administration of a single dose of a xenobiotic or several doses within 24 hours. Acute toxicity is expressed quantitatively by the $\mathrm{LD}_{50}$ parameter, which stands for the quantity of a xenobiotic that causes death of a half of the population of the studied laboratory animals. The animals' death is the parameter monitored in acute toxicity studies. The assessment also includes major directions of toxic effect, which is useful for further studies.

Detailed guidelines concerning the acute toxicity study procedure are included in an Annex to the regulation of the Minister of Health of 2003, according to which "tests on animals shall be carried out in a humane way, following the regulations on laboratory animals and international recommendations in the area. If several equal test methods exist, the one which requires using the least number of animals shall be applied".

The Organisation for Economic Cooperation and Development (OECD) has identified four methods of studying acute toxicity of substances and identifying the $\mathrm{LD}_{50}$ value. The OECD guidelines on study methods are updated periodically according to scientific progress and practical needs.

They accept the following methods:

1. classic method;

2. FD method - Fixed Dose Procedure (OECD guidelines No. 420);

3. ATC method - Acute Toxic Class Method (OECD guidelines No. 423);

4. Up-Down-Up method (OECD guidelines No. 425).

In the classic method, a xenobiotic is administered to groups of laboratory animals by ingestion or onto the skin. The clinical condition of the animals is observed for at least 14 days and all death incidents are registered. The toxic effect duration is identified, and autopsy of all animals is performed after the experiment.

Nowadays old toxicometric methods tend to be replaced by newer and more humane ones. A fixed-dose procedure is among the applied procedures. It uses doses of a toxic substance which cause a minimum (but observable) toxic effect but not the animals' death. The selected dose causing a moderate toxic reaction is administered to a group of animals for 14 days. The method only helps to identify the probable range of doses corresponding to $\mathrm{LD}_{50}$. Due to humane reasons, tests are also performed on in vitro cell lines as well as animal and human organs. 
An irritating effect of a substance is assessed through a local effect, i.e. limited to the area of direct contact of the toxic substance with the body. A chemical factor causing inflammation as a result of direct, prolonged or repeated contact with the skin, mucous membrane or other tissues is considered to be an irritating substance. A skin irritant causes reversible skin damage following a 4-hour exposure. If irreversible skin damage occurs after a 4-hour period (ulceration, bleeding, scabs, scars, epidermis and skin necrosis) it means the substance is caustic. Studies of irritating effect are conducted on glabrous skin or eye, if irritating action has not been revealed on the skin. An eye irritant causes changes fully reversible within 21 days, following application to the front area of the eye. Irreversible changes are caused by caustic substances. A sensitising effect is assessed on the skin of guinea pigs revealing relevant sensitivity to a known sensitising agent such as $\alpha$-hexylcinnamaldehyde. Studies of irritating effect on animal skin should be performed when there are valid premises indicating a need for such a study, and an analysis of available data does not bring conclusions or predictions of the substance effects (also if based on the results of studies of chemically similar substances or based on in vitro or ex vivo test). Substances with $2>\mathrm{pH}>11$ are not studied as their irritating effect is known in advance.

\section{Assessment of subacute toxicity at repeated doses for 28 days, including assessment of cumulative effect.}

4. Assessment of subchronic toxicity at repeated doses for $\mathbf{9 0}$ days.

Studies on subacute and subchronic toxicity are mainly intended to identify the nature of the substance effect on the body organs and systems, and establishing the maximum non-toxic dose. Studies are performed on larger groups of animals than for acute toxicity (usually 30 females and 30 males) for a longer time (usually 28 or 90 days). Different groups of animals receive different doses, whereby the lowest dose should not cause harmful effect and the highest one should have a toxic effect but not cause death of the animals. Similarly to acute toxicity studies, reactions of the animals are observed during the whole experiment and any cases of death or changes in the clinical condition are registered. The duration of toxic effect is identified and autopsy performed on all animals (which died naturally and were put down).

\section{Assessment of chronic toxicity in a 2 years' (or 12 months') test.}

Chronic toxicity of a chemical substance is the ability to cause a toxic effect in laboratory animals under chronic exposure. The exposure involves intermittent or continuous administration of the studied substance by different routes, five days a week for at least 12 months. The assessment of chronic toxicity can help to discover delayed effects and identify mechanisms of toxic effect (biochemical, haematological, physiological and neurological changes) as well as to identify critical organs i.e. the ones in which xenobiotics accumulate or which are damaged as a result of cumulated toxic effects. An assessment of 2 years' exposure facilitates initial identification of a potential carcinogenic effect of a compound. There are 
delayed effects of exposure to toxic substances which are defined as pathological processes developing in a body following a long (or short) latency period. Delayed effects can develop in organisms directly exposed to a chemical substance (somatic cells) or in subsequent generations (as a result of gene damage). The nature of the changes varies and the changes often come as tumours (carcinogenic effect). Secondary (generation) disorders tend to be genotoxic disorders (in the genetic material), embryotoxic disorders (pathological changes in the offspring) and teratogenic disorders (pathological changes in embryos or foetuses).

The purpose of chronic toxicity studies is to assess long-term effects of using small quantities of the reference substance. They are intended to identify concentrations safe at long-term exposure, i.e. identification of the highest acceptable dose (HAD) and highest acceptable concentration (HAC), which are essential parameters for development of OHS standards.

Studies are carried out in the same way as for subchronic toxicity but a single study lasts much longer and takes 2 years (at least 12 months). Once the observation is complete, the same biological and morphological tests as in subchronic toxicity studies are performed, and the carcinogenic effect is additionally investigated to identify genotoxicity of the compound.

\section{Assessment of delayed effects by:}

- studying of genotoxic effect;

- studying of carcinogenic effect;

- studying the teratogenic effect;

- studying the impact on fertility, reproduction and offspring.

The purpose of a mutagenic study is to assess the ability of a chemical compound to cause mutation in human DNA, which means its carcinogenicity. Not all carcinogens are identified this way as some of them cause tumour development leaving a cell genome intact. Tests are carried out on animals, cell cultures, bacteria, fungi and plants.

A study of teratogenicity i.e. adverse effect of a substance on a foetus is performed on pregnant animals, mainly on rodents. Any potential congenital malformations caused by a xenobiotic are assessed up to three months from the end of pregnancy.

Impact on fertility and reproduction is assessed to evaluate toxic effect of a substance on the functions of the reproductive organs, insemination, delivery and feeding. A three-generation study is carried out to examine reproductive toxicity of a substance. Animals of both sexes obtain the same xenobiotic doses as in chronic toxicity studies for 2 months and then are coupled. The offspring is then observed in their lifetime for 21 days, and their behaviour and all biochemical parameters evaluated. Then, they are put down for further analysis. The parents' generation is still monitored for the impact of the studied xenobiotic and reinseminated after a few weeks. A random group of the second litter and parents' generation is selected and the same study procedure is repeated. 


\section{Assessment of neurotoxic effect.}

Lipophilic and phosphorous organic compounds are major compounds subjected to neurotoxic effect tests. Study methods used for neurotoxicity assessment in animals include the following tests:

- behavioural (measurement of spontaneous motor activity, testing simple unconditional reactions and conditional instrumental reactions);

- electrophysiological (electrical phenomena occurring in tissues and organs are recorded and analysed, along with measurement stimuli conduction rate and electroencephalographic tests);

- morphological (morphological changes of the nervous tissue in histopathological preparations);

- biochemical (mainly used to explain the mechanisms of toxic effect of a compound on the nervous system).

\subsection{Absorption of xenobiotics}

There are many ways of a living organism exposure to toxic effect of foreign substances with a potential toxic action. Most substances reveal toxic effect after penetrating into the body and reaching a relevant concentration in the most sensitive organs. Only some compounds reveal a local effect, with no need to penetrate. A toxic substance penetrating into the body, regardless of the exposure route, is distributed (transported) and subjected to biotransformation (biochemical transformations) to be finally excreted from the body.

\subsubsection{Xenobiotics exposure routes}

Xenobiotics can penetrate into the body via different routes:

- oral (p.o. - per os);

- inhalation (inh. - inhalation);

- intravenous (i.v. - via intervenosa);

- dermal (cutanous, derm);

- subcutanous (s.c. - via subcutanea);

- topical (p.c. - via percutanea);

- intramuscular (i.m. - via intramuscularia);

- intraperitoneal (i.p. - via intraperitonealis);

- through mucosal membranes - conjunctiva, nose, anus or vagina.

Under industrial (environmental) conditions, the basic routes of xenobiotics absorption include: respiratory tract, alimentary tract and skin. The way of xenobiotics penetration into the body mainly depends on the route of exposure and the substance physical form. 
Liquid or solid substances can penetrate into the body through the alimentary tractor skin. Gaseous xenobiotics, such as vapours or aerosols, are mosteasily absorbed in the respiratory tract, while vapours and gases can also be resorbed through the skin. Aerosols accumulate easily on hairy skin and penetrate into the body.

\subsubsection{Absorption in the respiratory tract}

Xenobiotics in a gaseous form (vapours and aerosols) are absorbed in the respiratory tract. Lungs are the main area of xenobiotics resorption due to their strong vascularisation and large absorbing surface (estimated as $90 \mathrm{~m}^{2}$ ) as well as the fact that alveoli are built of thin permeable membrane with poor selective properties. Absorption is quick and highly effective. Toxic compounds absorbed this way penetrate in an unchanged form directly into the blood stream as they avoid biotransformation bypassing the hepatic circulation.

There are a number of factors affecting the resorption rate of toxic substances in the respiratory tract, including:

- concentration of xenobiotics in the air;

- lung ventilation;

- air/blood partition coefficient;

- speed of changes and poison excretion from the body;

- physical form of the substance and the size of its particles;

- solubility in water.

Based on the value of a toxic substance concentration in the air, the dose absorbed in the respiratory tract can be calculated. The following formula is used to that end:

$$
\mathrm{D}=\mathrm{R} \times \mathrm{W} \times \mathrm{C} \times \mathrm{T}
$$

where: D - absorbed dose (mg), R - compound retention in the lungs expressed as a fraction, $\mathrm{W}$ - ventilation of the lungs in $\mathrm{m}^{3} / \mathrm{h}, \mathrm{C}$ - concentration of the compound in the air $\left(\mathrm{mg} / \mathrm{m}^{3}\right), \mathrm{T}$ - exposure duration $(\mathrm{h})$.

The absorbed dose calculated this way is an approximate value, as all values in the formula are only estimated ones.

Breathing intensity depends on the body need for oxygen. Physical effort (intensive work, physical training) increases the demand. Greater volumes of air and hence a higher concentration of a xenobiotic are introduced into the lungs. Cardiac output rises during physical effort, which increases the rate of transporting the absorbed substance to organs and tissues with the blood. It also causes more intense xenobiotic absorption in the respiratory tract.

The quantity of toxic substance penetrating from the inhaled air into the blood depends on its solubility in the blood and other tissues, which is assessed 
based on the value of the blood/air partition coefficient. Gases highly soluble in blood, i.e. having a high value of the blood/air partition coefficient, diffuse into the blood easily, which means that their absorption increases as lung ventilation becomes more intense. Gases with low value of the blood/air partition coefficient (hardly soluble in the blood) diffuse into the blood, and increased lung ventilation boosts their resorption only slightly, since the blood is fully saturated with the substance. For such substances, absorption may increase with faster blood flow in the lungs.

Absorption of toxic substances in the respiratory tract depends on the physical form of the substance. Gases and vapours are absorbed by diffusion. Resorption depends on the particle size. Large dust particles, with diameters over $5 \mu \mathrm{m}$ deposit in the oronasal cavity and can be removed by expectoration or cleaning of the nose. The expectorated particles can be removed from the body or swallowed and absorbed in the alimentary tract. Non-expectorated particles stay in the upper sections of the respiratory tract where they are slowly resorbed. Particles with diameters ranging from 1 to $5 \mu \mathrm{m}$ are deposited in the trachea and bronchi. Aerosols with particle sizes up to $1 \mu \mathrm{m}$, which penetrate into the alveoli, have the greatest toxicological importance.

Hygroscopicity of the compound and its solubility in water, which makes for over $90 \%$ of mucus covering the surface of the respiratory tract, plays a major role in resorption of liquids. Dusts of compounds hardly soluble in water (such as lead sulphates and silicates) can be absorbed in the respiratory tract through pinocytosis. Non-soluble dusts can be removed from the respiratory tract owing to ciliary transport upward the respiratory tract, which usually takes several hours. The physical half-life of non-soluble dust in the alveoli lasts much longer, up to hundreds of days.

Solubility in water greatly determines the place of vapour or gas resorption in the respiratory tract. Hydrophilic substances (such as ammonia and hydrogen chloride) dissolve in the mucilage layers already in the upper sections of the respiratory tract. After dissolving, gas particles diffuse into epithelium cells of the respiratory tract and further into the capillary vessels located below epithelial cells to be transported to the tissues with the blood. Particles of lipophilic gas (soluble in lipids) (such as nitrogen oxides and phosgene can dissolve in the respiratory tract secretion only slightly and that is why the majority of them stays in the respiratory tract and travels down the respiratory system where they can be absorbed by the large surface of alveoli and penetrate into the capillary blood.

\subsubsection{Absorption from the alimentary tract}

The alimentary tract can be divided into three major sections differing for the speed, efficiency and specific nature of absorption. They are the oral cavity with oesophagus, stomach and intestines. 
Toxic compounds highly soluble in water (e.g. cyanides, nicotine, nitroglycerine, strychnine, phenol and alcohols) are absorbed in the oral cavity owing to good vascularisation of the mucous membrane. They stay in the oral cavity only for a short time which is not sufficient for the quantity of the absorbed substance to be significant. On the other hand, substances absorbed from the oral cavity are not subjected to the action of digestive enzymes in the alimentary tract and are absorbed bypassing the hepatic circulation, which means they are not metabolised in the liver and stay in a biologically active, unchanged form in the body for a longer time.

In the stomach chemical substances mix with food, gastric acids, digestive enzymes and bacteria, which significantly affects biological activity of the compound and can affect its toxicity. For instance nitrates, which are practically non-toxic, are transformed into highly toxic nitrites by microorganisms in the alimentary tract. The presence of chyme in the stomach affects substance toxicity by impacting its absorption. Absorption from the alimentary tract is weakened by formation of complexes with proteins. Presence of lipids or alcohol in the chyme can intensify absorption of such toxic substances as phosphorus or pesticides. A low $\mathrm{pH}$ value of gastric acid (about 1 ) contributes to absorption of substances of low acidity (slightly dissociated) and alkaline ones in the stomach. Nondissociated forms are highly soluble in lipids and penetrate through biological barriers easily by diffusion. Alcohols are examples of substances fairy well absorbed in the stomach.

Intestines have the highest absorption capacity. Xenobiotics are absorbed in intestines via different transport mechanisms such as passive diffusion, diffusion through pores, facilitated transport, active transport and pinocytosis in the intestinal villi. Efficient absorption in the intestines is fostered by a very large absorptive surface of the mucosa, estimated as $200-300 \mathrm{~m}^{2}$ in humans, and high variability of the intestinal chyme reaction from low acidic in the small intestine to low alkaline in the final sections. There are mechanisms which can improve the process of a xenobiotic absorption in the intestines. Proteins in the intestinal mucous membrane act as active carriers of elements essential for the body such as apoferritin which transports Fe. They can also transport elements with similar physical and chemical characteristics, including Co, Ni and Mn. Molecules with diameters of several nanometres can be absorbed through pinocytosis in the intestine villi and penetrate into the circulatory system via the lymphatic system and bypassing the hepatic circulation. Large molecules such as azodyes or polystyrene can be absorbed through phagocytosis by macrophages in the intestine walls.

Substances absorbed from the stomach and intestines, before entering the peripheral blood circulation, get to the liver via the portal venous system, where they are subjected to biotransformation processes reducing or increasing their toxicity. Some of them come back with the bile to the alimentary tract 
to be removed with faeces afterwards. Motor functions of the alimentary tract determine direct contact of the poison with the absorptive surface. If constipation occurs, poison absorption is higher as it stays in the intestines for a long time, while increased peristalsis (diarrhoea) makes the poison contact time with the alimentary tract membrane short, which limits the poison absorption.

\subsubsection{Absorption through the skin}

Skin is a protective barrier separating the body from the environment. Owing to the barrier, the body is able to resist exposure to xenobiotic doses as much as 1000 times higher than in the case of toxin ingestion or inhalation. Nevertheless, xenobiotic can penetrate into the body through intact skin, and toxic substances getting into the blood through the skin may cause poisoning of the whole body or even death. Dermal penetration is a long-lasting process depending on time. The time of exposure to a xenobiotic is the most important factor. Quick removal of a substance from the skin surface can prevent penetration of a large quantity of a xenobiotic.

Vapours and gases are first and foremost resorbed through the skin. They penetrate much easier than liquids or substances solved in them that can also penetrate through the skin tissue. Aerosols deposit easily on hairy skin, which facilitates their getting into the body.

Skin consists of the following three layers: epidermis (external layer), dermis (well-vascularised middle layer) and internal subdermal layer called hypodermis (composed of adipose tissue and connective tissue). Furthermore, skin anatomy identifies other skin appendages being potential spots of xenobiotic penetration, including hair follicles and sebaceous and sweat glands and ducts.

Toxic substances are absorbed through the skin by means of the following two mechanisms.

Transepidermal transport occurs directly through the epidermal cells and with regard to a large absorption area it is the main route of poison penetration into the body. Substances are absorbed in this form of transport via passive diffusion, going through a number of epidermal cell layers, while penetration through the stratum corneum built of tightly packed keratinocyte cells is a stage which limits the speed of the whole process. Organic compounds with a high oil/water partition coefficient and low ionisation degree such as aromatic and aliphatic hydrocarbons, aromatic amines and nitric compounds, phenols, phosphorous organic insecticides, carbon disulphate, carbon tetrachloride and tetraethyl lead are best absorbed via this route. Non-polar lipid compounds easily penetrate lipid areas of the membranes, while polar substances get inside the cells assisted by protein elements.

A number of factors affect the efficiency of absorption through the skin, including injury of the epidermis and skin condition, temperature, humidity 
and chemicals. Higher humidity and hydration of the cornified epidermis layer facilitate transport of polar compounds. Solids which do not penetrate through the skin can dissolve on the skin surface and be absorbed as dissolved substances. Chemicals acting directly on the epidermis and causing its damage or removal of the surface lipids and a change in its structure can contribute to a greater speed of xenobiotics penetration through the skin. They include acids, alkalis, detergents and organic solvents such as dimethyl sulfoxide (DMSO), methanol, ethanol, hexane, acetone and - primarily - a mixture of chloroform and methanol.

Transfollicular transport is a xenobiotic diffusion through hair follicles, and sweat and sebaceous glands and ducts which are an easy way of penetration. Transport through the skin appendages has a low significance for absorption of toxic substances as they cover only up to $1 \%$ of the skin surface. It is the absorption route of electrolytes, heavy metals and their organic complexes of low solubility.

\subsection{Distribution of toxic substances in the body}

Distribution is a wide term covering the xenobiotic route from absorption through to penetration through internal barriers of the body, transport, binding with plasma proteins, getting to the tissues and organs with the blood and selective cumulation.

The circulatory system plays the most important role in the distribution of toxins. Blood collects xenobiotics from their absorption spot, distributes them all over the body and participates in their excretion. The substance distribution rate in different organs depends on the cardiac output and vascularisation of the organ. Within a few minutes from absorption, the toxic substance reaches the organs with the highest blood flow (heart, lungs, liver, kidneys and brain). It takes more time (from several dozen minutes to several hours) for xenobiotics to penetrate into poorly vascularised organs such as the skin, skeletal muscles, connective tissue and adipose tissue.

Binding with plasma proteins, especially albumins (barbiturates, sulphonamides, ascorbic acid, $\mathrm{Cu}, \mathrm{Zn}, \mathrm{Ca}$ and histamine) and globulins (cyanocobalamin, polychlorinated insecticides, vitamins $\mathrm{A}, \mathrm{D}, \mathrm{E}$ and $\mathrm{K}$ ) makes an important element of a xenobiotic transport with the blood. It is a non-specific and reversible bond, and its strength depends on the compound affinity to the protein. With regard to a limited quantity of protein molecules and their binding spots, the degree of binding depends on the protein and xenobiotic concentration and occurrence of competitive substances with greater affinity. The KA association constant (also called a binding constant) identifies the affinity of a xenobiotic binding with a protein. Bonds essential for a xenobiotic distribution are characterised by the association constant value of at least $1 \times 10^{4}$. The association constant is calculated according to the formula: 


$$
\mathrm{KA}=[\mathrm{XB}] /[\mathrm{X}][\mathrm{B}],
$$

where: KA - association constant; X - free xenobiotic concentration; B - free protein concentration; $\mathrm{XB}$ - xenobiotic-protein xenobiotic concentration.

Binding of xenobiotics with proteins depends on the plasma $\mathrm{pH}$, which determines a protein ionisation degree; for instance a reduced quantity of barbiturates bonded with proteins is observed in acidosis.

Binding of a xenobiotic with plasma proteins weakens its action and affects elimination. Substances bonded with proteins do not penetrate through the walls of capillary vessels, which prevents their getting to the target organs and glomerular filtration. Binding with proteins does not limit tubular secretion or biotransformation.

Xenobiotic-binding proteins can be found in some organs, which contributes to a random deposition of toxins. Ligandin, a simple protein with high affinity to organic acids and corticosteroids, is present in the liver. Methallotioneins are proteins occurring in the liver, kidneys and mucous membrane, responsible for binding of such metals as $\mathrm{Cd}, \mathrm{Cu}, \mathrm{Zn}$ and $\mathrm{Hg}$.

Selective accumulation of xenobiotics can be important for selective cumulation of toxins. Toxins (or their metabolites) are accumulated in the body when a new dose of a xenobiotic is absorbed before the previous one has been excreted. Compounds with long half-life (which is the time necessary to reduce the substance concentration by half as compared to the initial value), taken for a long time, even in small doses tend to accumulate more often than other ones. The cumulation mainly applies to lipophilic substances (e.g. organochlorine insecticides and polychlorated biphenyls) which are stored in the adipose tissue. A sudden xenobiotic release from the reserve adipose tissue as a result of its instant metabolism e.g. in case of hunger or disease, may cause poisoning. Bone tissue is another example of a tissue prone to accumulate xenobiotics in a selective manner. It mainly accumulates lead, strontium, fluorides and radium. The elements are released in ionic exchange processes and following osteolytic activity. An increase in their concentration in the blood, and consequently in major organs (liver, kidneys and brain), may cause poisoning.

\subsubsection{Biological barriers}

A substance passing from its contact area with the body to the blood stream and its transport to different tissues require crossing of various barriers in a form of biological (cellular and subcellular) membranes. A semi-permeable protein and lipid membrane surrounding every cell in the body is a key control element of penetration of toxic substances into the tissues of different organs. 
The substances are transported through the plasma membrane via a number of mechanisms, depending on the physical and chemical properties of a xenobiotic.

Passive diffusion is the simples transport method involving free penetration of a substance through the semi-permeable membrane, according to the concentration gradient (from higher to lower concentration) and its rate increases with greater difference in the substance concentration on both sides of the membrane. Small, non-dissociated particles of compounds soluble in lipids (high oil/water partition coefficient) are prone for passive diffusion.

Transport through the pores facilitates penetration of fine molecules (up to $1 \mathrm{~nm}$ ) of hydrophilic substances and ions. They are transported with water and the transport rate depends on the difference in the hydrostatic or osmotic pressure on both sides of the semi-permeable membrane.

Facilitated diffusion is a form of transport similar to simple diffusion but it is supported by integral membrane proteins being selective carriers for individual ions and nearly all small organic molecules, except for lipophilic molecules penetrating the membrane by simple diffusion. Diffusion facilitating proteins are carriers which temporarily change their conformation, or protein canals forming hydrophilic canals for selected inorganic ions (mainly $\mathrm{Na}^{+}, \mathrm{K}^{+}, \mathrm{Cl}^{-}$and $\mathrm{Ca}^{2+}$ ) inside the hydrophobic membrane. This kind of transport does not require additional energy supply because it takes place according to the concentration gradient.

Active transport takes place against the concentration gradient, is assisted by membrane pumps, and requires supply of energy, mainly from high-energy ATP (adenosine triphosphate) bonds. A sodium-potassium pump $\left(\mathrm{Na}^{+} / \mathrm{K}^{+}\right.$ATPase) is the most typical example of an ionic pump.

Endocytosis involves penetration of a substance embedded inside a bubble formed from a fragment of a cellular membrane. The phenomenon is important in toxicology for aerosol absorption in the airways. If endocytosis applies to substances dissolved in the body fluids it is called pinocytosis, while endocytosis of solids in known as phagocytosis.

Intraorganic barriers being areas with limited permeability significantly reduce transport of toxic substances in the body. The blood-brain barrier which is a typical protein-lipid membrane constitutes such a protection in the central nervous system. It permeates small molecules of lipophilic toxic substances quite easily but forms a barrier for high molecular weight, ionised and hydrophilic compounds. A placenta is another example of such a barrier; it consists of metabolically active tissues forming a complex barrier between the mother's blood stream and the foetus. Placenta limits penetration of high-molecular compounds and ionised compounds not soluble in lipids. 


\subsection{Metabolism and excretion of xenobiotics}

\subsubsection{Biotransformation of xenobiotics}

Biotransformation of xenobiotics occurs in different tissues and organs, including intestines, kidneys, lungs and skin but first and foremost the reaction take place in hepatic microsomes. Enzymatic complexes related to the membranes of the smooth endoplasmic reticulum of hepatocytes, called microsomal monooxygenases, hydroxylases or oxidases of mixed functions, play a special role in biotransformation of xenobiotics by the liver. Other enzymes participating in biotransformation are located in the mitochondria and lysosomes. They include alcohol dehydrogenase and aldehyde dehydrogenase (which oxidise aliphatic and aromatic alcohols), carboxylesterases and amidases (hydrolysing esters, thioesters and amides).

The following three main components have been identified in the microsomal monooxygenase system:

- haemoprotein - cytochrome P-450;

- flavoprotein - cytochrome P-450 reductase;

- phospholipids.

The term cytochrome P-450 stands for a complex of different haemoproteins (haem is a prosthetic group in the enzyme) with a similar but not identical structure of amino acids catalysing molecular oxygen activation and its embedding in the structure of xenobiotics or substances of endogenic origin.

Spectrophotometric, immunological, electrophoretic and chromatographic tests revealed presence of many molecular forms of cytochrome P-450. Each form indicates organ specificity (e.g. CYP: $2 \mathrm{~A} 1,2 \mathrm{~A} 2$ and $2 \mathrm{~B} 3$ occurring only in liver, and $2 \mathrm{~A} 3$ only in lungs), and also partly different specificity of substrates. Presence of some forms of cytochrome P-450 depends on sex or age. Many chemical compounds cause an increase in expression of different forms of the cytochrome. They include polycyclic aromatic hydrocarbons, barbiturates, steroids, macrolide antibiotics, ethanol and acetone.

The purpose of biotransformation is to transform xenobiotics into more polar compounds which are better soluble in water and hence easier removed from the body. If the metabolites formed are less toxic than the original substance, the process is called detoxication, and if they become more active than the xenobiotic introduced, the process is called activation. Reactions catalysed by cytochrome P-450 may also produce free oxygen radicals which cause metabolic disorders in the hepatocytes together with reactive metabolites, resulting in hepatic steatosis, necrosis or neoplastic transformation of the cells.

Some xenobiotics do not undergo biotransformation, though. They include highly lipophilic compounds stored in the adipose tissue in an unchanged form. Similarly, highly volatile compounds such as ethyl ether and strongly polar compounds including phthalic acid are not subjected to biodegradation. 
Metabolic reactions of xenobiotics in the body occur in 2 phases:

- Phase I covers the following reactions: hydroxylation, oxidation, reduction and hydrolysis aimed to introduce polar groups $\left(-\mathrm{OH},-\mathrm{COOH},-\mathrm{SH}\right.$ and $\left.-\mathrm{NH}_{2}\right)$ into the lipophilic compound structure or to remove alkyl groups;

- Phase II - coupling; the previously formed metabolite with a polar group is coupled with endogenic compounds of very good solubility in water, e.g. glucuronic acid, sulphuric acid or glutathione, which results in formation of nonactive compounds with better solubility in water, higher molecular weight and then excreted with urine or bile.

\section{Reactions of phase I}

1. Hydroxylation - substitution of a hydroxyl group to the side chains of aromatic hydrocarbons (e.g. toluene transformation into benzoic acid) and barbiturates.

2. Epoxidation - binding of an oxygen atom to a double bond with epoxide formation. Epoxy metabolites are non-durable and react with macromolecules such as DNA, and hence may cause mutagenic or carcinogenic effect. Epoxy hydratase is an enzyme which transforms toxic epoxies and arene oxides, formed by oxidation of aliphatic and aromatic double bonds, to non-active diols.

3. Oxidative deamination - removal of an amine group and amine oxidation to ketone (e.g. amphetamine to phenyl acetone) under the influence of amine oxidase in the presence of HADPH cofactor and molecular oxygen.

4. Dealkylation - removal of alkyl groups.

5. Desulphurisation - oxygen substitution instead of sulphur; phosphorous organic insecticides and thiobarbiturates are subjected to biotransformation, usually to form more toxic metabolites.

6. S-oxidation - oxygen connection to sulphur, e.g. aliphatic and heterocyclic thioethers are transformed into sulphates and sulphoxides.

7. N-oxidation - oxidation of secondary and tertiary amines to $\mathrm{N}$-oxides by flavoprotein monooxygenase (oxidase of amines).

8. N-hydroxylation - primary and secondary aromatic amines are transformed into alkanolamines of nitric compounds (e.g. aniline $\rightarrow$ nitrobenzene).

9. Reduction of nitric and nitrogen compounds (nitrobenzene, chloramphenicol) to primary amines.

10. Reductive dehalogenation e.g. dichlorodiphenyltrichloroethane $(\mathrm{DDT}) \rightarrow$ DDE.

11. Single-electron oxidation and reduction result in formation of free radicals (reactive ones, having unpaired electron) e.g. single-electron oxidation (removal of 1 electron from a benzene ring causes formation of a cationic benzene radical), a single-electron reduction (electron binding to the benzene ring results in formation of an anionic benzene radical). 


\section{Reactions of phase II}

1. Glucuronidation - plays a major role in neutralisation of toxic substances; glucuronide residue from active glucuronic acid (UDP-glucuronic acid) with participation of enzymes - glucuronyl transferases - is bound by oxygen, nitrogen or sulphur group with substances having hydroxyl, carboxyl, amine or sulfhydryl groups. Many compounds including alcohols, phenols, sterols, alanine, aliphatic amines, carboxylic acids and benzoic acid are excreted as glucuronides.

2. Sulphatation - coupling with active sulphuric acid (3-phosphoadenosine 5 '-phosphosulphate); it applies mainly to phenols but also to aliphaticand aromatic amine compounds. Sulphur esters are formed after being coupled with sulphate, while hydrogen cyanide and cyanides become rhodanates (thiocyanates), while some metals form sulphides.

3. Coupling with glutathione (cysteine tripeptide - glycine - glutamic acid) by an active $\mathrm{SH}$ cysteine group. Epoxies of aliphatic and aromatic hydrocarbons, halogen aliphatic and aromatic hydrocarbons and halogen nitro compounds are coupled.

4. Methylation - coupling with a methyl group coming from active methionine (S-adenosylmethionine - SAM) formed as a result of activation by ATP. The process covers phenols, alcohols, aliphatic and aromatic amines, mercury, arsenic and selenium.

5. Acetylation - coupling with acetic acid. Acetyl coenzyme A, i.e. active acetate (acetyl group activation in the presence of ATP) combined with coenzyme $A$ is the source of acetyl group. Aromatic amines are subjected to the process.

6. Coupling with amino acids - applies to compounds containing hydroxyl groups. Many amino acids participate in the process (glutamine, serine, arginine, lysine) while glycine is the most important one.

There are various endo- and exogenous factors conditioning the speed and efficiency of biotransformation processes. General condition of the body, diseases, diet, age, sex and environmental factors affect the speed of the processes. Biotransformation is slower in newborns, elderly people and women, particularly in pregnant ones. Good nutrition and balanced diet determine the correct speed of biodegradation of toxins.

\subsubsection{Excretion of xenobiotics}

Toxic substances are removed from the body via different routes: through the respiratory tract (with exhaled air), excretory system (with urine), alimentary tract (with faeces and bile), while minor quantities of toxins are removed with sweat, saliva (actually in the alimentary tract), mammary glands and placenta. 


\section{Excretion through the respiratory tract}

Volatile substances including essential oils, ether, cyanides, nitrogen oxide, benzene, nitrobenzene and phenol are removed with the exhaled air. Excretion occurs by passive diffusion while its speed depends on the following factors:

- partial gas pressure in the alveoli and blood;

- degree of lung ventilation;

- cardiac output and blood flow rate through the lungs;

- value of the blood/air partition coefficient, where substances soluble in the blood (alcohol) are poorly removed with the air.

\section{Excretion by the alimentary tract}

Toxic substances absorbed in the alimentary tract get with the blood to the liver via the portal vein, where they are metabolised in the hepatocytes surrounding the bile ducts. Then they get into the bile or are returned to the blood and eliminated by the kidneys. They reach the lumen of the alimentary tract and can be excreted with faeces. Some substances excreted with the bile to the duodenum can be reabsorbed into the blood in the intestines. It applies to non-dissociated substances soluble in lipids. They come back to the liver and then to the bile until a polar metabolite is formed following metabolic transformations. Polar compounds and substances with high molecular weight are excreted with the bile. They are polycyclic aromatic hydrocarbons, dioxins, bile salts, glucuronides and bilirubin.

\section{Excretion by the urinary tract}

This is the most common elimination route of toxic substances; they are metabolites of organic and inorganic compounds with low molecular weight and soluble in water. The excretion process consists of the following three stages:

- glomerular filtration (passive filtration) in glomeruli capsules;

- passive tubular diffusion (reabsorption);

- active tubular transport (intratubular excretion).

Nearly all toxic compounds and their metabolites (both hydrophilic and hydrophobic ones) occurring in a free form in the plasma, i.e. the ones not linked to proteins, penetrate into the glomerular filtrate under passive diffusion. The filtration rate depends on the blood flow through the kidneys and increases with higher volumes of liquids drunk. With regard to low molecular weight, most drugs - except for albumin-related drugs - easily penetrate into the primary filtrate. The substances from the glomerule get into the tubule, where they can be reabsorbed or eliminated with urine.

About $99 \%$ of the primary filtrate volume is reabsorbed passively. Strongly ionised compounds and compounds not soluble in lipids are reabsorbed, while 
non-ionised lipophilic compounds are reabsorbed into the blood. That is why substances soluble in lipids are slowly removed from the body. For weaker acids or alkalis, the $\mathrm{pH}$ of urine is of key importance for the mechanisms. Urine alkalisation (administration of sodium bicarbonate or sodium lactate) increases elimination of acidic substances, while urine acidification (administration of ammonium chloride) boosts elimination of alkaline compounds.

Intratubular excretion is a process reverse to tubular absorption. Secretion of compounds to the renal tubule lumen occurs via active transport and only covers ionised substances non-soluble in lipids and protein-related compounds. Since the compounds are transported to the tubule lumen by means of active transport (against the concentration gradient), active intratubular excretion is the most effective mechanism of metabolites elimination by the kidneys - a compound concentration in the blood can be reduced to values close to zero. Nevertheless, a large group of compounds can use the same transport system, which may result in a competitive inhibition. The phenomenon can be used to prolong the substance action in the body (e.g. a drug) by administering a compound which inhibits drug elimination but it has adverse implications if prolonged action of toxins occurs.

Mechanisms of active transport are poorly developed in newborns and babies, which causes their high sensitivity to poisoning with toxic substances, in combination with low efficiency of the coupling processes (biotransformation phase II).

\section{Renal clearance}

The term "clearance" is used to identify the speed of substance elimination from the blood by the kidneys. It is the efficiency of renal function to clean the blood of the reference substance. The value is a resultant of the speed of all excretion processes and reabsorption in the kidneys. Clearance is expressed as the volume of blood completely cleaned of the substance in a unit of time; it is calculated according to the formula: $\mathrm{Cl}=(\mathrm{Cm} \times \mathrm{Wm}) / \mathrm{Co}$, where: $\mathrm{Cl}$ - clearance; $\mathrm{Cm}$ - substance concentration in urine; $\mathrm{Vm}$ - urine volume; Co - substance concentration in the blood. For instance, the compound clearance value of $10 \mathrm{ml} / \mathrm{min}$ means that $10 \mathrm{ml}$ of blood is completely purified of the compound.

The average blood flow rate in an adult is about $600 \mathrm{ml} / \mathrm{min}$, whereby $20 \%$ is filtrated in the glomeruli, which is about $120 \mathrm{ml} / \mathrm{min}$. Therefore:

- renal clearance of substances excreted only by glomerular filtration and not reabsorbed in the renal tubules (inulin) is about $120 \mathrm{ml} / \mathrm{min}$;

- renal clearance of substances excreted by glomerular filtration and active excretion in the tubules, not reabsorbed in the tubules ( $\mathrm{p}$-aminohippuric acid) is about $600 \mathrm{ml} / \mathrm{min}$;

- renal clearance of substances reabsorbed in the tubules will be low, i.e. less than $120 \mathrm{ml} / \mathrm{min}$. 


\subsection{Selected issues of detailed toxicology}

\subsubsection{Mechanisms of toxic effect}

Detailed toxicology deals with systematic studies and description of poisons, covering their division into groups based on similar chemical structure, properties or functional application. Mechanisms of action of only some toxic substances have been discovered so far. A mechanism of toxic action is a general term covering acute and chronic effects and sometimes also the delayed effects. The effects of toxic action of xenobiotics may apply to specific organs or system (neurotoxic, nephrotoxic and hepatotoxic effect). All these effects can be triggered by one or more mechanisms. The mechanisms of toxic action can be divided as follows:

1. Physical action;

2. Tissue hypoxia;

3. Inhibition of enzymatic reactions;

4. Blocking of receptors;

5. Active metabolites: covalent bonds;

6. Toxic action of free radicals;

7. Chemical carcinogenesis;

8. Immunological effect.

Physical action stands for the effect caused only by the poison presence when it does not react chemically with the biological system components. Chemical action is observed when the toxic effect depends on the occurrence of a chemical reaction between the poison and a specific biological system of the body.

1. Physical action is observed in lipophilic substances which penetrate the blood-brain barrier easily, causing disorders of the central nervous system and giving symptoms of a narcotic effect. Such xenobiotics deposit on the surface and inside the neural cell (neuron) membrane, impairing its correct contact with the external environment. Once the critical concentration of a xenobiotic has been exceeded, the neuron loses its ability to transmit nerve impulses, rendering a narcotic effect.

2. Tissue hypoxia. Appropriate quantities of oxygen need to be supplied to the tissues to reach the right value of the partial pressure of oxygen in the arterial blood. Under normal composition of breathing air (21\% oxygen) and normal atmospheric pressure $(760 \mathrm{~mm} \mathrm{Hg})$ partial pressure of oxygen in the arterial blood amounts to ca. $100 \mathrm{~mm} \mathrm{Hg}$. Relatively minor differences only cause discomfort but when the pressure drops below $70 \mathrm{~mm} \mathrm{Hg}$, it results in a loss of consciousness. Tissues in which intensive energy transformation takes place (brain and heart) are most vulnerable to the effects of hypoxia. Some toxic compounds (e.g. arsine, phenylhydrazine and chloronitrobenzene) may cause haemolysis of red blood 
cells hence reducing the quantity of active haemoglobin responsible for oxygen binding and transport. It mainly applies to acute poisoning. Impeded haemoglobin synthesis, which is a multi-stage process, can be another cause of a toxic decrease in the haemoglobin concentration. That is why the mechanism usually occurs in chronic poisoning caused for instance by lead. The haemoglobin level may also drop as a result of marrow cell damage. Such effect is attributed to benzene, cytostatic drugs and antimetabolites (which are compounds with a structure similar to a natural metabolite and impairing biochemical processes). Hypoxia may also result from haemoglobin inactivation. It can be caused by a toxic action of carbon oxide, nitrates (III), aromatic amines and other oxidants.

Carbon oxide reveals 200-300 times greater affinity to haemoglobin than oxygen so it can eliminate oxygen from combinations with haemoglobin even if its concentration in the air is low. Low concentration of $\mathrm{CO}$ in the exhaled air (over $0.1 \%$ ) may block over 50-60\% haemoglobin, resulting in a coma. A further increase in the level of carboxyhaemoglobin ( $\mathrm{HbCO}$ ) poses a risk of the respiratory centre paralysis; prolonged toxic hypoxia caused by carbon oxide may cause irreversible changes in the brain.

Oxidising substances such as sodium nitrate (III) and metabolites of aromatic amines oxidise haemoglobin to methaemoglobin. The oxidised form of haemoglobin (methaemoglobin, $\mathrm{MetHb}\left(\mathrm{Fe}^{3+}\right)$ ) is not able to transport oxygen, while oxidation of about $60 \%$ of haemoglobin results in death.

Carbon oxide, cyanides and azide inhibit cellular breathing, which occurs mainly in the mitochondria of cells using oxygen supplied to the tissues with the blood.

3. Inhibition of enzymatic reactions. Most enzymes are protein molecules whose structure includes an area with a specific arrangement of amino acids (active centre) conditioning catalyzation of biochemical reactions.

Toxic substances may impede enzyme activity by competitive inhibition, where they compete with the reaction substrate to bind with the enzyme in the active centre. The spatial structure of such inhibitors is similar to the natural substrate. The inhibition degree depends on the affinity of the substrate and inhibitor to the enzyme.

Many inhibitors bind with an enzyme or enzyme-substrate complex by connecting in a different place than the active centre (non-competitive inhibition). Some toxins are able to block functional groups of coenzymes participating in enzymatic reactions.

Esters and phosphoric acid derivatives, being inhibitors of acetylcholine esterase, are examples of toxic inhibitors of enzymes. Acetylcholine (ACh) is a neuromediator conducting impulses in the synapses of peripheral nerves and in the central nervous system. The ACh release to the synaptic space between two neurons transfers a nerve impulse between them. ACh is also released in the motor end-plate, i.e. between a neuron and muscle. ACh binding with 
a cholinergic receptor present on a post-synaptic cell causes an effector reaction such as a muscle contraction. The reaction comes to an end owing to a quick decomposition of excess acetylcholine by the enzyme - acetylcholine esterase (AChE). Esters and phosphoric acid derivatives (e.g. phosphorous organic pesticides) are able to form complexes with AChE, causing its inhibition. At high degrees of AChE inhibition, poisoning occurs following accumulation of acetylcholines in synapses and nerve ends. It also includes disorders of the central nervous system or even death as a result of the respiratory centre paralysis.

4. Blocking of receptors. Cellular receptors communicate information from the external environment into the cell. It takes place via signal molecules which bind with relevant receptors. They include hormones being neurotransmitters. The abovementioned acetylcholine released from a neurone into the synaptic space is an information carrier between a nerve cell and effector cell (muscle cell). ACh impacts the muscle cell via special receptors in the cellular membrane. There are two types of cholinergic receptors: muscarine and nicotine ones. Their name is related to selective stimulation by muscarine and nicotine, respectively. Acetylcholine stimulates both types of receptors as it is able to take different conformational forms. Muscarine is a simple alkaloid with a structure similar to acetylcholine, present in different species of toadstools, mainly in Amanita muscaria. Several minutes after eating such a mushroom, symptoms of stimulation of cholinergic muscarine receptors of smooth muscles and exocrine glands can be observed (lacrimation, salivation, sweating, dyspnoea, abdominal pain, diarrhoea, lower heart rate, cardiovascular collapse and coma).

Nicotine has an analogical stimulating effect on cholinergic nicotine receptors of the motor-end plate (causing contraction of striated muscles) and ganglia.

Chemical substances binding with a cellular receptor can also play a role of inhibitors, impeding cell functions. This way the receptors are blocked in a nonactive form preventing nerve impulse transfer. Such a mechanism of action can be observed in compounds being antagonists of the cholinergic nicotine receptor e.g. tubocurarine, an active substance present in a plant poison known as "currara" used by Indians to poison arrows, and nowadays used as a drug paralysing motor nerve ends. Bungarotoxin, a toxin present in snake venom, causing paralysis and respiratory insufficiency which may cause death, is among the abovementioned compounds.

A toxic substance can bind permanently with a presynaptic neurone membrane, blocking the canals which release ACh to the synaptic space. This is a mechanism of action characteristic of one of the strongest poisons - botulin (botulinus toxin) released by anaerobic bacteria Clostridium botulinum, developing in food products. Binding of the toxin in nerve ends is irreversible; muscles paralysed by the toxin behave as if they were deprived of neuration. 
5. Active metabolites: covalent bonds. High doses of some toxins cause necrotic changes in the liver parenchyma, which is caused by covalent bond of reactive metabolites with hepatocyte proteins, including enzymatic proteins. Active metabolites can also bind with molecules of nucleic acids and lipids. Acetaminophen and bromobenzene reveal toxic action based on covalent bonding mechanism.

6. Toxic effect of free radicals. Free radicals are particles containing at least one unpaired electron. Free radicals are formed in the body under physiological conditions e.g. in the mitochondrion respiratory chain. If the conditions are favourable, despite their high reactivity the molecules do not pose any hazard for biochemical processes, since the body can use antioxidating mechanisms helping to maintain the red-ox balance. They include anti-oxidating enzymes (superoxide dismutase (SOD)), catalase, glutathione peroxidase, ceruloplasmin) and low molecular weight antioxidants such as glutathione, lipoic acid and uric acid. SOD catalyses the reaction of superoxide anion radical dismutation to hydrogen peroxide and molecular oxygen. Catalase assists in hydrogen peroxide decomposition. Glutathione peroxidase catalyses decomposition of hydrogen peroxide and lipid peroxides. A toxic effect is observed at twisted balance when the quantity of generated radicals exceeds the capacity of defence mechanisms. Under inflammation, in the case of injuries or different diseases, an uncontrolled increase in production of free radicals is observed. Toxic effect of free radicals is related to their ability to interact with the body molecules (proteins, nucleic acids, lipids and carbohydrates). Consequently, proteins lose their natural biological functions and properties (enzymatic, regulatory, building), the genetic material is subjected to mutations, while unsaturated fatty acids, which are particularly susceptible to oxidation, are fragmented to form toxic aldehydes. Carbon tetrachloride $\left(\mathrm{CCl}_{4}\right)$ is an example of a xenobiotic whose mechanism of action is based on a reaction of the formed radicals with fatty acids. Its active metabolites: trichlormethyl radical $\left({ }^{*} \mathrm{CCl}_{3}\right)$ and trichlormethylperoxide radical $\left(\mathrm{Cl}_{3} \mathrm{COO}^{*}\right)$ are responsible for formation of covalently linked adducts and peroxidation of lipids. Hepatic necrosis is among their effects.

7. Chemical cancerogenesis. Cancerogenesis is a complex, multi-stage process of neoplastic transformation, beginning with the process initiation and followed by tumour promotion and progression. Cancerogenic factors may act on each of the stages. Initiation involves changes (mutation) in the genetic material of the cell. The changes most often apply to genes controlling the cellular cycle and make the right cells transform into potential neoplastic cells. Initiating factors may include genotoxic compounds acting directly or through active metabolites. Active forms of chemicals created as a result of biotransformation are strongly electrophilic, which determines their high reactivity with DNA; this way covalently linked adducts are formed. The adducts cause DNA damage and permanent mutations occur unless the damage is repaired. It depends on the 
damage type and quantity and efficiency of the repair system. Genetic changes acquired by the cell can be latent for a long time, while the impact of genotoxic factors may reduce the time. Mutation becomes fixed, if the damage in the genetic material is transferred to the daughter cell. The second stage of a tumour development is promotion, which involves proliferation of cells in which the initial genetic changes were fixed. Growth factors, hormones and non-genotoxic chemicals can act as proliferation promotors. Tumour progression is the third stage characterised by increased invasiveness and capability to cause metastases, related e.g. to formation of subsequent mutations, mainly in the suppressor genes responsible for inhibition of cell proliferation.

Genotoxic carcinogens are divided into compounds directly reacting with the DNA (e.g. ethyleneimine, 1,2,3,4-butadiene epoxide, sulphur yperite and $\mathrm{N}$-methyl-nitrosourea) and indirect compounds whose metabolites are direct carcinogens reacting with the DNA (e.g. vinyl chloride, benzo(a)pyrene, 2-naphthylamine, dimethylnitrosoamine and aflatoxin B1).

Another group of cancerogenic compounds covers epigenetic (nongenotoxic) carcinogens:

- metal ions (Ni, Be, Cr, Pb, Co, Mg and $\mathrm{Ti}$ );

- hormones (including synthetic ones) - first and foremost they cause hormonal imbalance, and tend to act as proliferation promotors;

- immunosuppressive drugs - stimulate development of virus-induced tumours, transplanted tumours or metastatic foci (antilymphocyte serum, azapurine, 6-mercaptopurin);

- co-carcinogens - act together with direct or indirect carcinogens and can modify transformation of indirect carcinogens into direct ones (e.g. n-dodecane, $\mathrm{SO}_{2}$, ethanol, phorbol esters, asbestos);

- promotors: act when exposure to carcinogens ends and they intensify their effects (e.g. phorbol esters, phenol, bile acids, saccharin, o-sulphobenzoic acid imide).

8. Immunological effect. Chemical substances may cause allergic reaction and contribute to formation of antibodies.

\subsubsection{Toxicity of selected heavy metals and chemicals}

\section{Toxicology of heavy metals}

\section{ARSENIC}

In the past arsenic compounds would be used intentionally as a poison. Such practices were significantly limited owing to a method of arsenic detection, developed by Marsh in 1836. Nowadays, cases of acute poisoning with arsenic compounds are rare. However, the element is among top most dangerous environmental and industrial poisons. 
Arsenic is a metalloid which forms inorganic and organic compounds in oxidation states $-3,+3$ and +5 . Organic arsenic compounds are at least by one magnitude order less toxic than inorganic arsenic compounds and they are quickly eliminated from the body in an unchanged form. Inorganic trivalent As (arsenic trioxide; $\mathrm{As}_{2} \mathrm{O}_{3}$ ) is more toxic than the pentavalent one. Arsenic in a solution is more toxic than arsenic taken in a solid form or with food, most probably due to better absorption.

Arsenic is mainly obtained as arsenic trioxide, being a side product of copper ore, lead, nickel and gold melt, $80 \%$ of which is used for production of pesticides and $10 \%$ for glass production. It is also used in tanning and wood impregnation to protect it against insects and fungi. Arsenic compounds as semi-conductors find their application in electronics in production of microprocessors. Phenyl derivatives of arsenic accelerate the growth of animals and they are added to poultry and pig feed. Arsenic is an ingredient of many drugs, which are now being withdrawn and replaced with other ones.

Potable water and food of marine origin constitute a major environmental hazard. Inorganic arsenic compounds are absorbed from the alimentary tract with $55-95 \%$ efficiency, while absorption of compounds hardly soluble in water is lower. Organic arsenic compounds in the food of marine origin are absorbed with $75-85 \%$ efficiency. Polluted air near steelworks and power plants combusting coal with a high admixture of arsenic can be the source of the substance. Inhalation is the main route of absorption in occupational exposure, where arsenic in the air occurs primarily as trioxide. Its absorption efficiency in the lungs amounts to at least $40-60 \%$. According to the results of post-mortem, arsenic concentration in the lungs was as much as 8 times higher in employees of steelworks than in people not exposed to arsenic in their workplace, which can directly contribute to a higher incidence of lung cancer in the case of occupational exposure to arsenic.

Arsenic in the blood is mainly bound by erythrocytes, where its concentration is about 10 times higher than in the plasma. It also reveals high affinity to keratin in the skin and its appendages (hair, nails), where 20 times higher concentrations is observed.

Following biotransformation, arsenic compounds undergo red-ox reactions and methylation with participation of methyltransferases and S-adenosylmethionine or non-enzymatically. It is regarded as a kind of detoxication because organic arsenic compounds are less toxic, less reactive and excreted faster.

Arsenic is mainly excreted with urine. The assessment of exposure to arsenic is based on the measurement of As concentration in the urine. Arsenic is not cumulated in the human body. Elimination of arsenic bound in some tissues (e.g. skin) lasts much longer than in the case of general systemic arsenic. Considering the fact that the daily hair growth is about $0.1-0.4 \mathrm{~mm}$, the time of poisoning with arsenic can be estimated based on the distance of its accumulation spot from the hair root. 
Acute poisoning - the lethal dose of $\mathrm{As}_{2} \mathrm{O}_{3}$ for humans is $70-180 \mathrm{mg}$ $(1-3 \mathrm{mg} / \mathrm{kg}$ body weight). Poisoning by ingestion is revealed by stomach and intestine injury, severe vomiting and diarrhoea (often with rectal bleeding). Dehydration of the body may result in a shock. Other symptoms include muscle spasms, swelling of the face and cardiac dysfunction.

Chronic toxicity applies to occupational exposure, mainly in high inhalation doses (concentration of several hundred $\mu \mathrm{g} / \mathrm{m}^{3}$ ). The symptoms include a characteristic garlic breath, perforation of the nasal septum, pharyngitis, laryngitis and bronchitis, cardiac dysfunction and Raynaud's syndrome. In people exposed in their workplace or taking As in water and food, the most typical symptoms of poisoning include skin hyperpigmentation and hyperkeratosis of the palms and soles. Long-term exposure causes necrosis of the limbs following peripheral circulation impairment (known as blackfoot disease).

Delayed effects - the carcinogenic effect of arsenic in humans is well documented and it is known that long-lasting exposure causes cancer of the skin, lungs, urine bladder, kidneys and liver. The valid HAC value for arsenic and its inorganic compounds amounts to $0.01 \mathrm{mg} / \mathrm{m}^{3}$ as per arsenic. It does not eliminate the risk of lung cancer incidence. The WHO has identified As concentration in potable water as $10 \mu \mathrm{g} / 1$. The risk of liver, lung, kidney or urine bladder cancer for people drinking water containing $50 \mu \mathrm{g}$ As/l for their whole life is 13 per 1,000 people, while for water containing $500 \mu \mathrm{g} / 1$ of arsenic it is 13 cases per 100 people.

\section{CADMIUM}

Cadmium is a chemical element from the group of transition metals, occurring in minor quantities in the rocks and soil. It can be found in zinc, lead and copper ores. Fossil fuels such as hard coal contain large quantities of $\mathrm{Cd}$. Owing to valuable physical and chemical, and physical properties such as high resistance to corrosion, low melting point and good electric conduction it is widely used in industry, e.g. for production of batteries, coating of metals, in electronics, lithography, production of dyestuffs, metal alloys and in control rods of nuclear reactors. Apart from inappropriate storage and processing of battery cells, the main emission sources of harmful cadmium compounds include treatment of metal ores, combustion of coal and other fossil fuels and using phosphorus-based fertilisers.

$\mathrm{Cd}$ can be absorbed by inhalation or ingestion. Food is the main source of cadmium for the general population (except for smokers). It is assumed that after smoking one pack of cigarettes a human body absorbs about $5 \mu \mathrm{g} \mathrm{Cd}$. Inhalation exposure has a high significance in occupational exposure.

Inhaled or ingested cadmium is bound by plasma proteins to be quickly transferred to the liver and kidneys. Cd absorption from the alimentary tract in humans is quite low and amounts to about 5\%. Data obtained in autopsies 
revealed that the highest quantities of $\mathrm{Cd}$ absorbed for many years accumulate in the initial section of the small intestine. Cadmium in the liver and kidneys is bound by a cellular protein of low molecular weight - metallothionein and in this form it is not toxic for cells. Cadmothionein released from the liver to the blood is also reabsorbed in the kidneys. Cadmium half-life in the body is very long - about 20 years. It means that cadmium is accumulated in the body for the majority of life. Excretion with urine is the main route of $\mathrm{Cd}$ elimination from the body. $\mathrm{Cd}$ concentration in the urine increases with age and results from the element concentration in the kidneys. Cadmium excretion increases dramatically when $\mathrm{Cd}$ concentration in the kidneys exceeds the critical level and renal tubules are damaged.

Cadmium is much more toxic than arsenic. It affects the kidneys by damaging their tubules and glomeruli, causes anaemia and disease of the bones (osteoporosis). Furthermore, it reduces insulin secretion and increases oxidation of lipids (which causes higher production of free radicals). It has an adverse effect of the circulatory system.

The symptoms of acute poisoning following inhalation include fever, headache, sore throat and pain in the chest, respiratory dysfunction, cough and conjunctivitis. The resulting pulmonary oedema may cause death and once it does not persist, interstitial pneumonia develops. The symptoms of ingestion include vomiting, diarrhoea and strong pain in the abdomen.

Chronic toxicity. Under occupational exposure and at extremely high environmental exposure (Japan), cadmium contribution to bone diseases seems to be evidenced. In the province of Toyama, Japan, where rice was grown in fields fertilised by wastewater from an industrial plant containing high volumes of cadmium, symptoms described as "Itai-Itai" disease were reported. They included strong pain of the joints and bones, mainly the backbone and lower extremities as well as a characteristic waddling gait. Osteomalation was among the observed lesions in the bones - it stands for softening of the bones as a result of insufficient mineralisation, while osteoporosis developed following a loss of the bone mass. Consequently, there were numerous cases of bone fractures and deformations.

Delayed effects. Cadmium and its compounds are considered to be human carcinogens and are listed by the experts from the IARC (International Agency for Research on Cancer) in the first group of factors with epidemiologically proven carcinogenic effect. The HAC value for cadmium and its inorganic compounds (fumes and vapours) valid in Poland is $0.01 \mathrm{Cd} / \mathrm{m}^{3}$ as per cadmium.

\section{LEAD}

Lead forms connections at +2 and +4 oxidation degree. Occupational exposure to lead and its compound is mainly observed in steelworks, where lead is molten and processed. Atmospheric air can be a significant source of exposure for a general population, particularly in areas with heavy vehicle traffic as lead 
is a fuel additive. Fortunately the use of the additive has been greatly limited in recent years. Lead can also be found in paints and chemical dyestuffs, whereas minor quantities of lead are used for production of soldering alloys, printing types, brass, shields protecting against ionising radiation and bullets.

About $40 \%$ of lead from the air is captured in the respiratory tract. Pb ingested with food is absorbed in the alimentary tract with up to $10 \%$ efficiency in adults and up to $50 \%$ in children. Iron, calcium and phosphates in food reduce the efficiency of absorption from the alimentary tract, while ascorbic acid increases $\mathrm{Pb}$ absorption.

Lead absorbed into the blood binds with erythrocyte membranes, which reduces their survival, to be later distributed in parenchymatous organs. Transfer to the muscle tissue and skin takes place a bit more slowly, while it is the slowest into the teeth and bones. $\mathrm{Pb}$ is accumulated in the bone tissue during our whole life, and the teeth and bones contain about $90 \%$ of the total lead present in the body. Permanent embedding of $\mathrm{Pb}$ into the bone tissue involves replacement of calcium ions in a hydroxyapatite crystal $\left[\mathrm{Ca}_{10}\left(\mathrm{PO}_{4}\right)_{6}(\mathrm{OH})_{2}\right]$. Lead penetrates placenta easily. It is mainly excreted in the urinary tract and in a limited extent also with faeces.

The haematopoietic and peripheral nervous system are critical systems in adults in case of lead poisoning, while in children it is the central nervous system. Lead inhibits activity of many enzymes causing impairment of processes mainly in the haematopoietic system. In the nervous system in turn it causes demyelination and degenerative changes of axons. Besides people exposed in their work, children are particularly sensitive to lead poisoning.

Acute poisoning with lead occurs relatively rarely. The lethal dose of lead salt (acetate, carbonate) administered orally amounts to 20-30 g. Lead colic is the most common symptom of acute poisoning with lead. It is demonstrated by a sweet taste in the mouth, lack of appetite, dyspepsia, abdominal pain, low blood pressure and body temperature, pale skin and bradycardia. Lead poisoning may cause renal failure which is demonstrated by haematuria, albinuria and oliguria. Lead poisoning may also result in arrhythmia or myocardial infarction. In children, and sometimes in adults, lead encephalopathy causing stupefaction, irritability, headache, muscle tremor, hallucinations, memory disorders and lack of concentration can be observed. Further stages include convulsions, paralysis and coma. Immediate medical help is necessary if acute poisoning with lead occurs. Oral or intravenous chelation with EDTA is applied. If indicated so, gastric lavage can be performed using 3\% sodium sulphate with a large quantity of activated carbon. If encephalopathy or acute or chronic renal failure occur, haemodialysis is indicated. Opioids (e.g. codeine) are administered in cases of intestinal colic.

Chronic poisoning, when lead gets accumulated in the body for a long time, is mainly characterised by damage to the nervous system, skin, smooth muscles, kidneys and bone marrow. Lead colic can also occur in the course of chronic lead poisoning as acute manifestation of chronic poisoning. 
Delayed effects of lead poisoning reveal its mutagenic action as well as inhibition of DNA synthesis and repair. Mutagenic action of lead was observed in experimental animals (kidney and brain cancer). Lead was classified by the International Agency for Research on Cancer (IARC) as 2B factor (probably carcinogenic to humans).

Lead level in the blood is the basic parameter used in the assessment of exposure to lead. According to the WHO recommendations, the value should be less than $200 \mu \mathrm{g} / 1$ in $98 \%$ of population, while the permissible concentration in children is $100 \mu \mathrm{g} / 1$. The highest permissible concentration in the workplace amounts to $0.05 \mathrm{mg} / \mathrm{m}^{3}$ for $\mathrm{Pb}$ and its inorganic compounds as per lead. Pregnant and breastfeeding women must not do jobs entailing contact with lead, regardless of its concentration in the work environment.

\section{MERCURY}

It comes as organic and inorganic compounds. Occupational exposure to mercury applies mainly to mercury vapours and occurs first and foremost in the mining sector, in chemical plants producing chlorine by mercury electrolysis and for production of dyestuffs and fungicides. Mercury is mainly used in electrical engineering (alkaline batteries, production of measurement equipment). Exposure of the general population to mercury is related to consumption of organic mercury compounds in the fish. Metallic mercury $\left(\mathrm{Hg}^{0}\right)$ in a vapour form is mainly absorbed in the respiratory tract, and in minor quantities also through the skin and after absorption into the blood it is oxidised enzymatically to $\mathrm{Hg}^{2+}$ in the presence of catalase. $\mathrm{Hg}^{0}$ contrary to $\mathrm{Hg}^{2+}$ is lipophilic, which means it easily penetrates the blood/brain and blood/placenta barriers. Therefore mercury, which was not oxidised in the blood, easily penetrates into the brain and foetus tissue and it is accumulated there. Brain is a critical organ for exposure to the metal vapours. The half-life of mercury in the body is several months and for the fraction deposited in the brain it can be up to several years. Mercury is mainly excreted with urine and faeces.

Acute poisoning with metallic mercury causes the respiratory tract insufficiency. Chronic exposure mainly causes symptoms of the central nervous system (hyperexcitability, depression, headache, muscle tremor, memory deterioration, insomnia and state of anxiety). Brain damage, i.e. mercury encephalopathy, can also occur. Gastrointestinal disorders and renal damage are rarely observed.

Poisoning with inorganic mercury compounds occurs rarely and usually via oral exposure. They result in the alimentary tract and renal disorders - albuminuria and haematuria as well as acute renal insufficiency. Chronic poisoning occurs in combination with exposure to metallic mercury vapours. Inorganic mercury compounds are absorbed from the alimentary tract and through the skin. Inorganic mercury is mainly deposited in the renal cortex, where it is bound by 
methallothionein. It is not toxic in this form and renal damage occurs only at mercury doses exceeding the capacity of its binding by the renal methallothionein.

Organic mercury compounds were used as fungicides to protect seed grain. Nowadays, cases of poisoning with mercury compounds mainly apply to eating fish. Accumulation in the food chain leads to water contamination with mercury, via aquatic flora and fauna into predatory fish in which the half-life of mercury is several hundred days. Absorption of organic mercury compounds from the alimentary tract in humans is very effective and the absorbed mercury binds in the blood mainly with erythrocytes, and then travels to the tissues. Organic mercury compounds demonstrate high affinity to the brain tissue. A characteristic feature or organic mercury compounds, considering their hydrophobicity, is their easy penetration through biological barriers.

\section{CARBON OXIDE}

Carbon oxide is a strongly toxic gas, common in nature. Poisoning with carbon oxide is the most common gas poisoning and among most frequent causes of lethal poisoning in general. Presence of carbon oxide tends to be difficult to be identified due to its characteristics (non-irritating, odourless and colourless, easily mixing with air at any ratio).

Carbon oxide is absorbed into the body through the respiratory tract, penetrates through the alveo-capillary barrier of the lungs and binds irreversibly with haemoglobin forming carboxyhaemoglobin $(\mathrm{COHb})$, which is unable to connect and transfer oxygen to the body organs. It causes tissue hypoxia of a degree proportional to the blood saturation with $\mathrm{COHb}$ and tissue demand for oxygen.

About $15 \%$ of absorbed $\mathrm{CO}$ remains outside the circulatory system, mainly in the heart and muscles as a combination with myoglobin. Carbon oxide is excreted by the lungs in an unchanged form.

The affinity of haemoglobin and myoglobin to CO is $200-300$ times greater than their affinity to oxygen. Symptoms of toxic action of $\mathrm{CO}$ result from hypoxia of the body and apply to many systems (cardiovascular, nervous and respiratory) and organs (liver, kidneys, muscles, organ of hearing, organ of vision and the skin), and tend to occur at $\mathrm{COHb}$ concentration in the blood over $20 \%$. At concentrations over $60 \%$ death occurs within several minutes.

Chronic poisoning may be caused by continuous exposure to low concentrations of $\mathrm{CO}$, which cause accumulation of microinjuries leading to permanent disorders (poor memory, permanent fatigue, appetite and sleep disorders and circulatory system malfunctions).

\section{SULPHUR DIOXIDE}

Sulphur dioxide is a colourless gas with a specific, irritating odour. As a combustion product of sulphur in the coal and exhaust fumes it significantly contaminates the air in industrial areas (smog). 
Even if strongly thinned, it denaturates proteins, which makes it a good disinfesting, disinfecting and fungicidal agent. Sulphur dioxide is used for cold storage purposes, for bleaching in paper-making, dyeing and textile industry, while in the food industry it is a common preservative (E220) used especially in wines.

$\mathrm{SO}_{2}$ is absorbed through the respiratory system and skin. It is a strong respiratory tract irritant. It easily dissolves in water forming sulphuric acid, and it also dissolves in methanol, ethanol and chloroform. As a gas highly soluble in water it easily penetrates through the mucous membranes of the respiratory tract. The formed sulphuric acid is responsible for strongly irritating effect on the mucous membranes of the eyes, respiratory tract (bronchospasm or chronic bronchitis and tracheitis) and the skin.

Owing to its pungent and irritating odour $\mathrm{SO}_{2}$ can be smelled easily and quickly and that is why cases of acute poisoning are rare. Exposure to concentrations of $20-30 \mathrm{mg} / \mathrm{m}^{3}$ causes severe stinging, lacrimation as well as redness and swelling of the conjunctiva. High concentrations may cause damage to the cornea. Skin irritation is demonstrated by redness, pain, burning and swelling. Poisoning by inhalation is demonstrated by cough, runny nose and sore throat but dyspnoea caused by swollen glottis, laryngospasm or (rarely) pulmonary oedema can also occur. Other symptoms may also include nausea, vomiting, diarrhoea, abdominal pain, headache, dizziness and anxiety.

Chronic poisoning related to long-term exposure to low concentrations of $\mathrm{SO}_{2}$ is often accompanied by the upper respiratory tract infection, abundant mucous secretion and conjunctivitis.

\section{HYDROGEN CYANIDE}

Hydrogen cyanide is a colourless liquid with a smell of bitter almonds. It dissolves easily in water, ethanol and ether. It occurs naturally as amygdalin in leaves and seeds of stone fruit (almonds, peaches, apricots, plums and cherries). $\mathrm{HCN}$ is used as a disinfecting and rodent control agent, and its salts - cyanides - are used in many technological processes.

Hydrogen cyanide is quickly absorbed via different routes: skin, respiratory tract and alimentary tract. Poisoning is revealed by a characteristic smell of bitter almonds in the exhaled air. HCN is metabolised in the body under the influence of thiosulfate sulfotransferase to thiocyanates (rhodanates) - compounds which are about 200 times less toxic than cyanide and excreted with urine.

After getting into the body, $\mathrm{HCN}$ dissociates into $\mathrm{H}^{+}$ion and cyanogen ions $\left(\mathrm{CN}^{-}\right)$, which reveal affinity to $\mathrm{Fe}^{3+}$ ions of cytochrome oxidase, and hence block the action of the respiratory chain and cellular respiration. Nervous system and cardiac muscle cells are particularly sensitive to hypoxia and that is why high doses of $\mathrm{HCN}$ cause an immediate loss of consciousness as a result of paralysis of the respiratory centre and cardiac arrest. Respiratory and circulatory insufficiency is 
preceded by a scratchy feeling in the throat and burning and bitter taste in the mouth, sialosis, numbness of the lips and larynx, muscular weakness, difficulty in speaking, headache and dizziness, nausea, vomiting, accelerated breath, palpitation and heaviness in the heart area, low pulse, mydriasis, exophthalmos and convulsions.

\section{ALIPHATIC HYDROCARBONS (INGREDIENTS OF CRUDE OIL AND NATURAL GAS)}

Aliphatic hydrocarbons in high concentrations have a narcotic effect and the power of their action increases for longer carbon chains. Short aliphatic hydrocarbons with up to 4 carbon atoms are gases which cause hypoxia and general anaesthesia, while the ones with a higher molecular mass are neurotoxic liquids. Aliphatic hydrocarbons with a branched chain and unsaturated aliphatic hydrocarbons have the strongest action. Nevertheless, the greatest hazard related to high concentrations of hydrocarbons is related to a risk of explosion.

A mixture of aliphatic hydrocarbons in a form of crude oil vapour is absorbed through the lungs and skin. Liquid crude oil is in turn absorbed from the alimentary tract.

Metabolites produced in biotransformation processes are mainly eliminated via kidneys, coupled with sulphuric acid, while crude oil compounds not subjected to biotransformation are eliminated with the exhaled air.

Hygiene standards for crude oil have not been developed but it is classified in Poland as a potential human carcinogen (i.e. category 2). Crude oil is a skin irritant and the lesions formed in about $1 \%$ of people turn into a skin cancer.

\section{CRUDE OIL DISTILLATION PRODUCTS (PETROL AND KEROSENE) USED MAINLY AS FUEL AND SOLVENTS}

Crude oil distillation products are easily absorbed from the respiratory tract, through the skin and alimentary tract. They have an irritating effect on the skin, mucous membranes of the eyes, alimentary tract and respiratory tract.

Aliphatic hydrocarbons are poorly metabolised in the body and that is why a significant part of the absorbed vapours of petrol and kerosene is eliminated through the lungs in an unchanged form.

Crude oil distillation products are lipophilic compounds with high affinity to the adipose tissue and cellular membranes, which facilitates penetration through the blood-brain barrier and leads to dysfunction of the nervous system.

Some fractions of crude oil distillates (e.g. paraffin-based distillates) are classified as category 1 carcinogens, i.e. substances with proven carcinogenic effect in humans. Extraction naphtha and mineral spirits (painter's naphtha) were classified in Poland as category 2 carcinogens. 


\section{CHLORINE DERIVATIVES}

As the molecular mass goes up, toxicity of chlorine derivatives of aliphatic hydrocarbons increases but their volatility decreases. Higher homologues with a higher content of chlorine are more dangerous at elevated temperatures.

The compounds are mainly liquid hydrophobic substances with a specific odour, which are used in the industry as solvents of organic compounds. Halogen derivatives of an aliphatic series are characterised by high chemical activity and are used for obtaining other derivatives. Halogen derivatives are chemical compounds used as semi-finished products to obtain important chemical compounds. Vinyl chloride is a gas applied in production of polyvinyl chloride.

First and foremost they constitute a hazard in occupational exposure. Chloroform is a hazard for the general population since it is formed during potable water conditioning using chlorine (the permissible dose of $\mathrm{CHCl}_{3}$ in potable water is $0.03 \mathrm{mg} / \mathrm{l})$. Under humidity, air and light it decomposes into strongly poisoning phosgene and hydrogen chloride. Chloroform is also known as an agent used for general anaesthesia but nowadays it is not popular for the purpose.

Chlorine derivatives of aliphatic hydrocarbons are absorbed in the respiratory tract, from the alimentary tract, through undamaged skin and mucous membranes (vinyl chloride is absorbed through the respiratory tract in a gaseous form). They quickly penetrate into the blood and other tissues and reach the highest concentrations in tissues rich in lipids, from which they are removed most slowly. They are mainly metabolised in the liver and their metabolites are primarily responsible for the toxic effect of the chlorine derivatives. For chloroform and carbon tetrachloride it is phosgene, for vinyl chlorine it is epoxy, which is highly reactive and in water solutions it is transformed into chloraceticaldehyde and glycol aldehyde, which are chemically active metabolites.

Acute poisoning with chlorine derivatives of the aliphatic order cause nonspecific narcotic effects whose intensity depends on the kind and concentration of the substances in the exhaled air. Initial symptoms may include irritation of the mucous membranes and conjunctiva, vomiting and headache. A period of excitation (anxiety, high arterial pressure, and fast heartbeat) is followed by a depressive effect on the central nervous system and loss of consciousness. Vinyl chloride causes a characteristic oversensitivity to cold, numbness and tingling of the hands and Raynaud's syndrome. Further consequences of acute or chronic poisoning with the compounds include lesions of body organs, e.g. fatty degeneration of the liver, renal insufficiency and cardiac muscle damage due to hypoxia.

They are carcinogens for laboratory animals. Most probably the compounds may cause delayed effects in humans but so far such an effect was only proven for vinyl chloride. IARC classified $\mathrm{CHCl}_{3}$ and $\mathrm{CCl}_{4}$ as $2 \mathrm{~B}$ class, i.e. probably carcinogenic to humans. Vinyl chloride was classified as a proven human carcinogen (category 1). 


\section{POLYCYCLIC AROMATIC HYDROCARBONS (PAHS)}

PAHs are a group of over 200 known compounds containing from 2 to 13 condensed benzene rings in a particle. PAHs are among major group of chemicals polluting the environments. PAHs mixed with water steam particles form smog. They are formed during incomplete combustion of all hydrocarbons except for methane. They occur in industrial raw materials and their products including coal tar, mineral oils, asphalt, carbon black and tar. Therefore occupational exposure to PAHs applies to such industry sectors as coke engineering, metallurgy, founding and petrochemical industry. They are mainly released to the environment during combustion of engine fuels (exhaust fumes), by abrasion of car tyres and asphalt, and during operation of coke ovens (heating in buildings) and waste incineration. Smoking of cigarettes and tobacco is a source of emission (and exposure) of the compounds. Natural factors such as volcano eruptions or great fires of forests also contribute to PAH formation (PAHs are emitted when wood from coniferous trees is burnt).

PAHs are formed in food during its thermal processing e.g. frying, baking, smoking, grilling and roasting. The higher the temperature and the longer the process duration are, the higher the content of PAHs in the finished food product is. Moreover, food additives used to improve organoleptic quality of smoked products are also a source of PAHs. Roasting of coffee beans causes formation of PAHs, too. PAHs may occur in food products as a result of cultivation or animal breeding (fishing in contaminated water) near areas with highly polluted environment.

The majority of PAHs occur in the air as vapour and aerosols, and some of them can also deposit on the dust. In such a form they can penetrate into the body through the respiratory tract and depending on the particle size they can deposit in different sections of the respiratory tract. PAHs can get into the body through the alimentary tract on contact with food and tap water. Under occupational exposure, direct absorption through the skin is possible following a direct contact.

After penetrating into the body (regardless of the absorption route), they are quickly transferred with the blood into the tissues and organs. Owing to their hydrophobic properties they easily penetrate through the cellular membranes and accumulate in the adipose tissue.

The compounds are characterised by chronic toxicity, which means that even a high single dose is not harmful but only a long-lasting and regular exposure to minor doses can become a cause of diseases. The most toxic PAHs include benzo(a)pyrene, dibenzo(a,h)anthracene and benzo(b)fluoranthene. Epidemiological studies revealed a relationship between occupational exposure to PAHs and higher prevalence of cancers.

Studies on several PAHs metabolites revealed that they are mutagenic and carcinogenic substances. The mechanism of tumour formation under the influence of PAHs involves covalent bonding of metabolites with a cell's DNA or RNA. 
Benzo(a)pyrene is the most studied hydrocarbon in the PAH group. In relation to the severity of its carcinogenic effect and common occurrence in the environment it was considered as an indicator for the whole PAH group. The highest acceptable concentration for PAH (as a total of 9 carcinogenic concentrations of PAHs multiplied by carcinogenicity factors) was established in Poland at $0.002 \mathrm{mg} / \mathrm{m}^{3}$. The highest acceptable concentration for PAH is the same as the highest acceptable concentration for benzo(a)pyrene itself.

\section{DIOXINS}

A group of organic compounds being oxantrene derivatives is commonly known as dioxins. They are polychlorinated dibenzo-p-dioxins (PCDD) composed of two benzene rings linked by two oxygen atoms and from one to eight chlorine atoms connected to benzene rings. Polychlorinated dibenzofurans (PCDF) are similar compounds, also included in the group of dioxins. 7 out of 75 PCDDs are highly toxic. 2,3,7,8-tetrachlorodibenzodioxin (TCDD) is the most dangerous compound.

Dioxins are hydrophobic compounds, easily soluble in organic solvents. They are most toxic among all synthetic substances. They are formed as a side product in production of organic chlorine compounds (pesticides, herbicides and chlorophenol derivative), during wood combustion (forest fires) and any organic compounds containing chlorine (combustion of municipal and hospital waste). With regard to low solubility of dioxins in water, they are absorbed onto the surface of particles suspended in water and fall with particles on the bottom. Studying the degree of water contamination is based on identifying concentration of dioxins in the bottoms. Plant protection products are also a source of water and soil contamination with dioxins. PCCD accumulation in plants is low but dioxins accumulate in large concentrations in aquatic animals such as snails and fish where their concentrations exceed the concentration identified in water by $1 \times 10^{3}$ times. Hence eating fish (oily fish in particular) from contaminated water reservoirs is a significant exposure factor.

Dioxins are mainly absorbed through the alimentary tract but also through the respiratory tract with dust. With regard to their hydrophobic character they travel with blood plasma lipoproteins and easily penetrate into cells. In the body they accumulate in the liver and adipose tissue. Metabolic transformations cause dechlorination and formation of hydroxy derivatives and coupled compounds, excreted with bile and faeces. The mean half-life is about 10 years and it depends on the adipose tissue weight.

Characteristic symptoms of toxic effect of dioxins on humans include:

- skin lesions (chlorine acne, proliferation and cornification of epidermis and formation of corneous-sebaceous cysts);

- impaired hormone balance, including changes in the thyroid hormone balance, elevated TSH level, decreased level of male sex hormones, impaired function of male and female gonads; 
- immune system malfunction;

- embryotoxic and teratogenic action.

IARC classifies TCDD as group 1, i.e. human carcinogens.

\section{PESTICIDES}

They are substances of synthetic or natural origin used to protect plants against pests, diseases and weeds but also to combat parasites in breeding animals, harmful rodents etc. The use of chemical pesticides to protect plants is based on employing the toxic properties of chemical substances against biological species regarded as harmful.

It can be inferred that pesticides are intended only to destroy organisms considered by humans as unfavourable and harmful. But complete selectivity of pesticide action cannot be achieved in practice, which means that there is always a risk of toxic effects. Unfortunately, despite great variety of applied pesticides, they all reveal a harmful impact on living organisms. Exposure to pesticides occurs already during their production but first and foremost it is related to their common use in agriculture.

With regard to high number and heterogenic nature of the group of compounds called pesticides, it is not possible to characterise in the study the toxicity of all substances used for plant protection. There are different divisions of pesticides and it depends on the acquired assessment criteria but the basic classification of pesticides includes the following:

1. functional classification of pesticides depending on the target species;

2. classification based on chemical structure;

3. classification based on the toxicity scale assessment;

4. division into natural and synthetic pesticides.

\section{Classification according to species}

1. Zoocides - agents intended to combat animal pests, including:

- insecticides (agents used to kill insects),

- acaricides (agents killing mites),

- ovicides (agents designed to destroy eggs of insects and mites),

- afficides (agents killing aphids),

- nematicides (agents used to kill nematodes),

- larvicides (agents targeted against larval life stage of insects),

- molluscicides (pesticides against molluscs),

- rodenticides (agents against rodents),

- attractants - attracting agents,

- repellents - repelling agents;

2. Bactericides - agents killing bacteria;

3. Herbicides - weed killing agents, including growth regulators:

- total - damaging the whole population of plants,

- selective - eliminating specific plant species, 
- growth regulators - inhibitors, stimulants,

- defoliants (agents used to remove plant lists),

- desiccants (plant drying agents),

- deflorants (agents used to remove excessive quantities of flowers);

4. Fungicides - fungicidal and fungistatic agents.

\section{Classification based on chemical structure}

\section{Inorganic pesticides}

- herbicides: ammonium sulphamidate, borax, sodium chlorate,

- fungicides: alkaline copper (II) chloride, Bordeaux mixture, sulphur,

- arsenic insecticides: Paris green $3 \mathrm{Cu}\left(\mathrm{AsO}_{2}\right)_{2} \mathrm{xCu}\left(\mathrm{CH}_{3} \mathrm{COO}\right)_{2}$, lead arsenate $\mathrm{PbHAs}_{4}$,

- fluoride insecticides: cryolite $\mathrm{Na}_{3} \mathrm{AlF}_{6}$, sodium fluoride $\mathrm{NaF}$, sodium fluosilicate $\mathrm{Na}_{2} \mathrm{SiF}_{6}$;

\section{Organic pesticides}

- herbicides: heterocyclic cationic compounds, triazines, phenylurea derivatives, dinitroaniline derivatives, phenoxyacetic acid derivatives, phenylcarbamate derivatives,

- fungicides: metallic derivatives of ethylenebis(dithiocarbamates),

- insecticides: chlorine derivatives of hydrocarbons, pyrethroids, organophosphorus compounds and carbamates.

\section{Classification based on toxicity scale}

Based on the regulation of the Minister of Agriculture and Food Economy of 12 March 1996.

\begin{tabular}{|c|c|c|c|}
\hline \multirow[b]{2}{*}{$\begin{array}{c}\text { Toxicity } \\
\text { class }\end{array}$} & \multicolumn{3}{|c|}{ Acute toxicity } \\
\hline & $\begin{array}{c}\mathrm{LD}_{50} \\
\text { oral } \mathrm{mg} / \mathrm{kg} \text { b.w. }\end{array}$ & $\begin{array}{c}\mathbf{L D}_{50} \\
\text { dermal } \mathrm{mg} / \mathrm{kg} \text { b.w. }\end{array}$ & \begin{tabular}{|c|}
$\mathrm{LD}_{50}$ \\
Inhalation $\mathrm{mg} / \mathrm{l} / 4 \mathrm{~h}$ exposure \\
\end{tabular} \\
\hline $\begin{array}{l}\text { I. Very } \\
\text { toxic T+ }\end{array}$ & $\leq 25$ & $\leq 50$ & $\begin{array}{l}\leq 0.25 \text { aerosols } \\
\leq 0.50 \text { gases and vapours }\end{array}$ \\
\hline $\begin{array}{l}\text { II. Toxic } \\
\mathrm{T}\end{array}$ & $25<\mathrm{LD}_{50} \leq 200$ & $50<\mathrm{LD}_{50} \leq 400$ & $\begin{array}{l}0.25<\mathrm{LD}_{50} \leq 1 \text { aerosols } \\
0.50<\mathrm{LD}_{50} \leq 2 \text { gases and vapours }\end{array}$ \\
\hline $\begin{array}{l}\text { III. Harm- } \\
\text { ful Xn }\end{array}$ & $200<\mathrm{LD}_{50} \leq 2000$ & $400<\mathrm{LD}_{50} \leq 2000$ & $\begin{array}{l}1<\mathrm{LD}_{50} \leq 5 \text { aerosols } \\
2<\mathrm{LD}_{50} \leq 20 \text { gases and vapours }\end{array}$ \\
\hline $\begin{array}{l}\text { IV. } \\
\text { Slightly } \\
\text { toxic }\end{array}$ & $>2000$ & $>2000$ & $\begin{array}{l}>5 \text { aerosols } \\
>20 \text { gases and vapours }\end{array}$ \\
\hline
\end{tabular}




\subsubsection{Environmental exposure of selected toxins}

\section{Catastrophic exposure:}

- Mass release of dioxin 2,3,7,8-tetrachlorodibenzo-p-dioxin (TCDD) was released from a factory in Soveso near Milan in July 1976; ca. $16 \mathrm{~kg}$ of the dioxin polluted the area of $3-4 \mathrm{~km}^{2}, 28,000$ people were struck by the disaster.

- Mass release of methyl isocyanate from Union Carbide factory in Bhopal, in December 1984 - 200,000 people were exposed and 2,500 of them died.

- Oil spill

1977 - "Ekofisk" drilling rig on the Norwegian Sea - 12,000 tons of crude oil were spilt.

16 March 1978 the "Amoco Cadiz" oil tanker wrecked off near the French coast - ca. 220,000 tons of crude oil were spilt.

3 June 1979 - catastrophe of the "Ixotoc" drilling rig in the Mexican Bay - ca. 1 million tons of crude oil were spilt.

24 March 1989 - "Exxon Valdez" oil tanker near Alaska - ca. 40 million litres of crude oil were spilt.

1991 - during the Persian Gulf War oil wells destroyed in Kuwait, which resulted in spilling of ca. 38 billion litres of crude oil into the Gulf waters.

\section{Endemic exposure:}

- Organic mercury compounds - "Minamata” disease

Vinyl chloride plant in Kyushu (Japan), 1953 - poisoning of the inhabitants of a cottage at the Minamata Bay after eating fish; over 700 people came down with the disease and $40 \%$ died.

Industrial wastewater, the Agano river (Japan), 1964 - over 500 people were poisoned after eating fish.

Mercury-based fungicides, Iraq, Pakistan, Guatemala, 1971-72 - eating flour from toxic grain, 6400 people, 480 died.

- Hexachlorobenzene

Eating poisoned grain, Turkey, 1956 - 3000 people, 10\% died.

- Cadmium - "Itai-Itai" disease

Contamination of the Untsu river with wastewater in Japan, 1995 - irrigation of rice fields with the river water resulted in a 10-times increase in the cadmium level in the rice.

- Triorthocresol phosphate (TOCP)

In 1930 food and (mainly) alcohol were counterfeited in the USA, ca. 20,000 people were poisoned.

In 1959 oil was counterfeited in Morocco and over 10,000 people were poisoned. 
- Toxic oil syndrome

Frying oil containing $50 \mathrm{ppm}$ aniline and $2000 \mathrm{ppm}$ acetanilide was used in Spain $-25,000$ people were hospitalised and 400 died.

- Polychlorinated biphenyls (PCB)

consumption of oil from rice bran, Japan (1968) (the incident was called Yusho i.e. rice disease) - 1800 people were poisoned; a similar mass poisoning occurred in Taiwan in 1979.

- Polybrominated biphenyls (PBB)

Incidental contamination of grain and feed, USA, 1973 - 250,000 cows, 1.6 million chickens and hundreds of pigs died.

\section{Using toxins to exterminate humans:}

- During the Vietnam War, the US Air Force soldiers sprayed a herbicide called Agent Orange containing high concentration of dioxins, including TCDD - being among the most toxic dioxins. It was used to destroy plants to facilitate detecting guerrillas from a plane. The objective was also to damage the crops to deprive the guerrillas of food. The "Operation Ranch Hand", in which rainbow herbicides were used, lasted 10 years (1961-1971). Over 75 million litres of herbicides were used not only in Vietnam but also in Laos and Cambodia. Almost 20\% of forest areas were sprayed. Unfortunately, the results of the spraying operation have become a contemporary issue due to contamination of the herbicides with TCDD. The Vietnamese calculated that almost 5 million people were exposed to direct action of the agent, i.e. they were directly exposed to the sprayed agent or consumed contaminated food and water. Almost 400,000 people died or were permanently injured. The spraying caused long-term effects of permanent genetic disorders. Deformed, physically and mentally disabled children are still born in the contaminated areas. The American soldiers and pilots of the aircrafts used for spraying also experienced negative health effects. A higher incidence of cancer, skin diseases and respiratory tract diseases was observed among them.

- Ground has remained contaminated until nowadays in the areas of the former US military bases where the herbicides were stored. Dioxins penetrate into the soil and ground water as well as into the crops, and consequently the whole food chain is contaminated, which causes skin diseases, lung cancer, laryngeal cancer and prostate cancer.

- In 2004 the same dioxin - TCDD, which is among most toxic artificially obtained substances, was used to poison then-presidential candidate of Ukraine, Victor Yuschenko.

- In 2002 during a siege in the Moscow Dubrovka Theatre 40 terrorists and 129 hostages died as a result of using sleeping gas containing phentanyl and 3-methylphentanyl (painkillers and anaesthetic drugs with opioid effect). 
- In the war between Iraq and Iran (1980-1988) the Iraqi used chemical weapon on a mass scale (mainly chemical warfare - yperite and tabun), which caused numerous and often lethal injuries, including severe burns and blinding.

\section{References}

Adriano D.C., Trace elements in terrestrial environments: biogeochemistry, bioavailability and risk of metals (2nd ed.), Springer Verlag 2001.

Dilda P.J., Hogg P.J., Arsenical-based cancer drugs, Cancer Treat. Rev., 2007, no. 33.

Franco S.S., Nardocci A.C., Gunther W.M.R., PAH biomarkers for human health risk assessment: a review of the state-of-the-art. Cad Saude Publica, 2008, no. 24.

Garvey J.S., Metallothionein: a potential biomonitor of exposure to environmental toxins, [in:] Biomarkers of Environmental Contamination, J.F. McCarthy, L.R. Shugart (eds.), Chelsa, England 1990.

Gonzalez F.J., Tukey R.H., Drug metabolizm, [in:] Brunton L.L., Lazo J.S., Parker K.L. Goodman \& Gilman's the pharmacological basis of therapeutics (11th ed.), New York, McGraw-Hill: Medical Publishing Division 2006.

Hauser B., Schrader G., Bahadir M., Comparison of acute toxicity and genotoxic concentrations of single compounds and waste elutriates using Microtox/Mutatox test system, Ecotoxicol, Environ. Saf. 1997, no. 38(3).

Indulski J., Lutz W., Krajewska B., Biomarkery zagrożeń zdrowotnych osób zamieszkujących obszary o wysokim stopniu skażenia kancerogennymi substancjami chemicznymi, t. XIII, Sekcja Wydawnictw Instytutu Medycyny Pracy, Łódź 1996.

Keddy C.J., Greene J.C., Bonnell M.A., Review of whole-organism bioassays: soil, freshwater sediment, and freshwater assessment in Canada, Ecotoxycol, Environ. Saf. 1995, no. 30.

Klaassen C.D., Toxicology: the basic science of poisons (7th ed), Casarett \& Doull's 2008.

Kostka G., Zastosowanie biomarkerów w ocenie ryzyka zdrowotnego związanego z narażeniem na środowiskowe chemiczne kancerogeny, Roczniki Państwowego Zakładu Higieny 2003, no. 54.

Mielżyńska D., Narażenie na substancje o działaniu kancerogennym. Biomarkery narażenia. Ocena środowiskowego ryzyka zdrowotnego, zarządzanie i nadzór nad ryzykiem oraz komunikacja o ryzyku, Szkolenie zorganizowane w ramach Krajowego Programu Działań na Rzecz Środowiska i Zdrowia, Instytut Medycyny Pracy i Zdrowia Środowiskowego, Sosnowiec 11-12 grudnia 2000.

Samanta S.K., Singh O.V., Jain R.K., Polycyclic aromatic hydrocarbons: environmental pollution and bioremediation, Trends Biotechnol., 2002, no. 20.

Seńczuk W., Toksykologia współczesna., Wydawnictwo Lekarskie PZWL, Warszawa 2006.

Silins I., Hogberg J., Combined Toxic Exposures and Human Health: Biomarkers of Exposure and Effect, International Journal of Environmental Research and Public Health, 2011, no. 8 .

Staszewska-Sikorska A., Gorgoń J., Jankowski R., Korcz M., Krupanek J., Ryzyko zdrowotne od środowiskowe, jako miernik zrównoważenia relacji środowisko - człowiek, Środowisko a Zdrowie, 2005, no. 7. 
Stec M., Kurzeja E., Kościołek A., Góral-Pawłowska K., Zagrożenia wynikające z narażenia na dioksyny i dioksynopodobne polichlorowane bifenyle, Probl. Hig. Epidemiol., 2012, no. 93.

Traczewska T.M., Biologiczne metody oceny skażenia środowiska, Oficyna Wydawnicza Politechniki Wrocławskiej, Wrocław 2011.

Vasan S.R., Biomarkers of Cardiovascular Disease: Molecular Basis and Practical Considerations, Circulation 2006, no. 113. 